News, Noise and Indian Business Cycle

Ashima Goyal and Abhishek Kumar

Indira Gandhi Institute of Development Research, Mumbai April 2019 


\title{
News, Noise and Indian Business Cycle
}

\author{
Ashima Goyal and Abhishek Kumar
}

Email(corresponding author): ashima@igidr.ac.in

\begin{abstract}
New Keynesian Dynamic Stochastic General Equilibrium (DSGE) models with various specifications of technology, markup and interest rate shocks are estimated with Indian data using Kalman filter based pure and Bayesian likelihood estimation. Preference and interest rate shocks are found to be important for output determination whereas markup and interest rate shocks are important for inflation. News, such as contained in stock market variables and arising from anticipated interest rates, affects growth of gross domestic product. Interest rate shock is anticipated at horizon of one quarter and out of total variance explained by interest rate shock, one third is due to the anticipated shock. Anticipated interest rate shock diminishes the role of preference shock in output determination. Markup shock has a large share, very low persistence but is correlated. There is evidence that permanent component of technology is not well anticipated, and once we incorporate that technology shocks become more important for determination of output although it still remains much below US levels. Implications for policy are drawn out.
\end{abstract}

Keywords: DSGE; India; News; Noise; Technology Shock; Learning; Anticipated Shocks; Kalman Filter; Maximum Likelihood; Inflation; Monetary Policy

JEL Code: E31; E32; E52; E57

\section{Acknowledgements:}

The paper is developed from Abhishek Kumar's M.Phil thesis. We are grateful for useful comments from two examiners and thank Reshma Aguiar for assistance. 


\section{Introduction}

The Indian economy has transformed in recent decades. The Indian business cycle is no more a monsoon business cycle and is now well connected to the global business cycle. Significant changes in monetary policy have followed economic transformation. Reserve Bank of India has adopted flexible inflation targeting with an interest rate as the instrument.

Global central banks have extensively used New Keynesian models for insights on monetary policy making. New Keynesian models include many shock processes that compete with the real-businesscycle model's technology shock in driving aggregate fluctuations. In Indian context there has been very limited amount of work using New Keynesian framework. Goyal and Kumar (2017) find a limited impact of technology shock on output while interest rate shocks have higher impact on output and inflation in in India compared to the US. They also have evidence that markup shocks are not persistent.

Anticipated shocks (news shocks) have been found to be important in explaining business cycle fluctuations (Beaudry and Lucke, 2010, Grohe and Uribe, 2012). Grohe and Uribe (2012) find anticipated shocks account for about half of predicted aggregate fluctuations in output, consumption, investment and employment in United States. Gomes et al. (2017) suggest that anticipated monetary policy shocks explain variance of real variables and the best model is with anticipation over a two period horizon ${ }^{1}$. Zeev et al. (2017) suggest that anticipated shocks in terms of trade account for around $25 \%$ of business cycle fluctuation in emerging economies.

Our objective is to extend Goyal and Kumar (2017) to explore the role of anticipated technology and other shocks in explaining business cycle fluctuations in India ${ }^{2}$. The limited impact of technology shocks is a puzzle, which allowing for anticipated shocks may help resolve. A significant part of technological progress maybe anticipated. First, we provide evidence from a simple regression regarding the importance of news shocks. Second, we extend the model in Goyal and Kumar (2017) by bringing independent anticipated technology, interest rate and markup shocks (these shocks comes from different distribution compared to corresponding surprise shocks). We also bring correlated anticipated technology, interest rate and markup shocks (these shocks comes from the same distribution) as in Walker and Leeper (2011), which is effectively a moving average representation for

\footnotetext{
${ }^{1}$ Evaluating the impact of anticipated monetary policy shock is also important because forward guidance is now an important aspect of monetary policy implementation. Conventional monetary policy shock (surprise) is the deviation from policy rule whereas anticipated monetary policy shock is anticipated deviation from policy rule. In case of forward guidance, if the agent correctly anticipate that the policy rate would be different than what would be warranted by the future economic condition then it should immediately affect economic outcomes. This could work through other channel apart from the direct central bank communication through forward guidance. If agents know that central bank responds to a particular shock and that shock is correlated then a significant portion of future interest rate movement can be anticipated. In case if the central bank overreacts to the shock then the future anticipated interest rate could be higher than what is warranted by the prevailing economic condition in the future and thus will have real effects.

${ }^{2}$ Table 6 in Appendix C gives the forecast error variance decomposition in Goyal and Kumar (2017), which is our baseline model.
} 
shocks.

Third, we bring the issue of learning in technological progress. Emerging market economies (EMEs) face a lot of uncertainty, incuding in technological progress. Acemoglu et al. (2003) and references therein document that EMEs are characterized by poorer institutional quality and greater political uncertainty compared with advanced economies (AEs). This view is also supported by the earlier literature on EME business cycles that hinged on uncertain duration of reforms, particularly in the context of exchange-rate-based stabilisation programs as explained in Boz et al. (2011). Therefore, we bring a learning problem in which the agents observe only the sum of permanent and temporary components and do not observe components individually. They observe a noisy signal of the permanent component of technological progress. The learning problem in technological progress is based on Blanchard et al. (2013). This representation contains both news and noise ${ }^{3}$ and help us in understanding the role of uncertainty in technological progress in the Indian business cycle.

Results suggest that innovation in stock market variables such as stock price index, price earning ratio and market to book value ratio significantly affect the growth of gross domestic product. Anticipated interest rate shocks are also important and out of total variance explained by interest rate shock, one third is due to the anticipated interest rate shock. There is also evidence that significant portion of the interest rate movement is anticipated in advance. Anticipated technology shock does not significantly change the model fit. We have evidence of two kinds of models, one in which the entire variance is associate with surprise technology shock and other one with entire variance associated with news in technology shock.

Moving average term in technology shock process as in Walker and Leeper (2011) does not significantly change the fit of the model but moving average term in interest rate and markup significantly affects the fit of the model (suggesting that technology shock is not correlated whereas markup and interest rate shocks are). Interest rate shock becomes more important for the output determination at the expense of preference shock. The markup shock process has very low persistence supporting a moving average rather than an autoregressive term in the markup shock process. Imperfect knowledge about permanent component of technology shock makes technology shock more important for output determination at the expense of the interest rate. This partially resolves the puzzle of low share of technology shock in explaining output variance. Not only does the decomposition of technology shock into permanent and transitory matter but also the uncertainty of the permanent component plays an important role.

Section 2 gives estimates obtained from the simple regression. Section 3 gives the baseline

\footnotetext{
${ }^{3}$ There is an issue with disentangling fundamentals from belief (equivalently the noise shock) based on the news and noise representation of Blanchard et al. (2013) as shown in Chahrour and Jurado (2017). A news shock is an anticipated change in future fundamentals and there is a possibility that it may not always be fully realized in future due to other unforeseen disturbances. Chahrour and Jurado (2017) suggest an equivalent noise representation of the model which leads to correct estimation of the contribution of fundamentals and of noise. According to Chahrour and Jurado (2017) the estimates in Blanchard et al. (2013) give a slightly lower importance to noise shocks.
} 
model. Section 4 explains the various extension of the baseline model being estimated. Section 5 gives the overview of the data and is followed by results in Section 6 and conclusion with implications for policy in Section 7. Appendix A gives the log linearised baseline model and the linearised version of the various extension being estimated. Appendix $B$ discusses the method of taking the model to the data and is followed by graphs and tables in Appendix C.

\section{Evidence from a Simple Regression}

We use real gross domestic product, a stock market variable (stock price index, price earning ratio or market to book value ratio of Bombay Stock Exchange benchmark index, BSE Sensex), consumer price index and the rate of interest (15-91 days treasury bills rate). Real gross domestic product and consumer price index has been adjusted for seasonality.

Gross domestic product should identify innovations to productivity, (ii) stock market should help isolate news shock, iii) consumer price index should be able to identify markup or cost push shock and iv) interest rate should help identify monetary policy shock. Gross domestic product and the consumer price index has been seasonally adjusted. BSE Sensex, gross domestic product and consumer price index have unit root and so we take first difference of natural logarithm for them. Other variables are used in log levels.

Table 1: Regression Estimates: With BSE Sensex

\begin{tabular}{cccccc}
\hline & F0.Growth & F1.Growth & F2.Growth & F3.Growth & F4.Growth \\
\hline Sensex_G & $0.0000966^{* *}$ & $0.0000817^{*}$ & 0.0000236 & -0.0000628 & 0.0000547 \\
& $(2.13)$ & $(1.76)$ & $(0.50)$ & $(-1.38)$ & $(1.14)$ \\
L.Sensex_G & 0.0000718 & 0.0000164 & -0.0000650 & $0.0000823^{*}$ & -0.0000564 \\
& $(1.55)$ & $(0.35)$ & $(-1.36)$ & $(1.77)$ & $(-1.15)$ \\
TBR & -0.00134 & -0.00117 & -0.00812 & -0.00408 & -0.00544 \\
& $(-0.25)$ & $(-0.22)$ & $(-1.49)$ & $(-0.77)$ & $(-0.98)$ \\
L.TBR & -0.00425 & -0.00706 & -0.00130 & -0.00594 & -0.00187 \\
& $(-0.78)$ & $(-1.26)$ & $(-0.23)$ & $(-1.09)$ & $(-0.33)$ \\
L.Growth & 0.136 & 0.0719 & 0.115 & $-0.253^{* *}$ & 0.0707 \\
& $(1.25)$ & $(0.65)$ & $(1.03)$ & $(-2.32)$ & $(0.62)$ \\
L.CINF & 0.0348 & 0.0188 & -0.0347 & -0.0170 & 0.0530 \\
& $(0.67)$ & $(0.35)$ & $(-0.65)$ & $(-0.33)$ & $(0.97)$ \\
Const & $0.0243^{* * *}$ & $0.0309^{* * *}$ & $0.0338^{* * *}$ & $0.0408^{* * *}$ & $0.0292^{* * *}$ \\
& $(4.09)$ & $(5.09)$ & $(5.54)$ & $(6.87)$ & $(4.69)$ \\
\hline $\mathrm{N}$ & 87 & 86 & 85 & 84 & 83 \\
\hline \multicolumn{5}{c}{ t-values in parentheses “* $\mathrm{p}<0.10 * * \mathrm{p}<0.05^{* * *} \mathrm{p}<0.01^{\prime \prime}$} & \\
\hline
\end{tabular}

Notes: F0.Growth is current growth of gross domestic product. F1.Growth - F4.Growth is one to four quarter ahead growth of gross domestic product. Sensex.G and L.Sensex.G is current and lag growth rate of BSE Sensex. TBR and L.TBR is current and lag 15-91 days treasury bills rate. L.CINF is lag quarter on quarter consumer price inflation. L.Growth is lag growth of gross domestic product.

Our identification is based on interest rate being purely exogenous, stock market variable re- 
sponding to the interest rate, growth of gross domestic product responding to the interest rate and stock market and finally inflation responding to all three of them. We present regression estimates with growth in BSE Sensex in Table 1 and the estimates with price earning ratio and market to book value is given in Table 2 and 3 in Appendix C.

As evident from Table 1 the stock price index significantly affects the current growth rate and one period ahead growth in gross domestic product suggesting a role for news shocks in the business cycle. We have controlled for interest rate and lagged interest rate. This has the expected sign but is not significant. Even lagged growth of gross domestic product does not turn out to be significant but it has a positive sign (although small in magnitude), which indicates low growth persistence. Lag of consumer price inflation is positive, although not significant, pointing to inflation output trade off justifying the Phillips curve to be used in the model in Section 3.

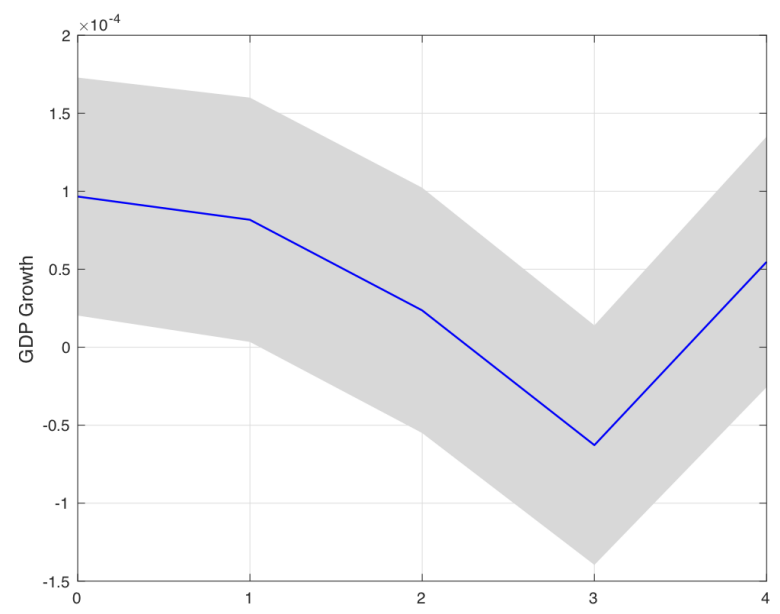

Figure 1: Response of gross domestic product growth to Sensex growth (news) shock. Shaded area represent one standard deviation confidence band.

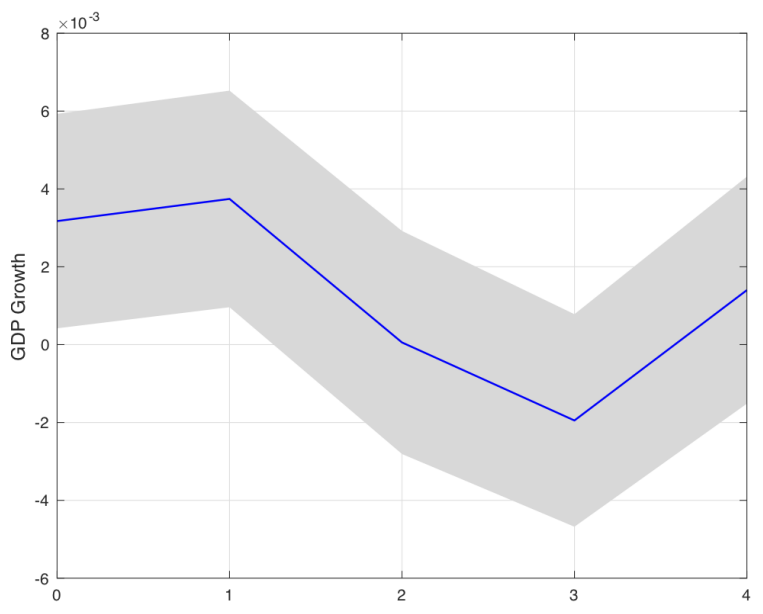

Figure 2: Response of gross domestic product growth to market to book value (news) shock. Shaded area represent one standard deviation confidence band. 
These coefficients are used to construct the impulse response at one standard deviation confidence interval, given in Figure 1. Figure 2 and 3 give impulse responses for market to book value and price earning ratio. Innovation to these stock market variables are expected to contain news about the future as stock prices and both these ratios are based on the discounted value of future earning. Therefore, positive innovation in all of these implies better future prospects. These figures suggest the role played by news shock in Indian business cycle.

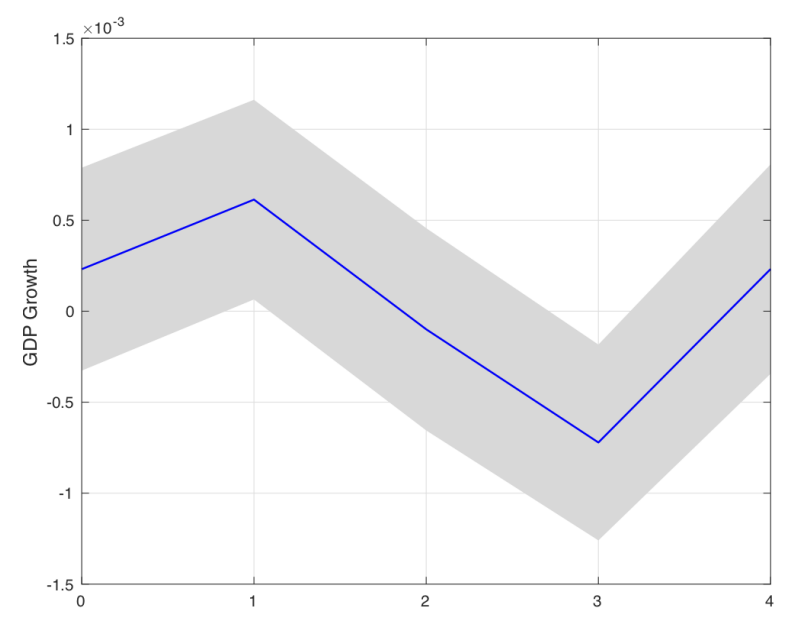

Figure 3: Response of gross domestic product growth to price earning (news) shock. Shaded area represent one standard deviation confidence band.

\section{Baseline Model}

The model is based on Ireland (2010). The economy consists of a representative household, representative finished good producing firm, continuum $(i \in[0,1])$ of intermediate goods producing firms and a central bank ${ }^{4}$. Intermediate goods producing firms operate in a monopolistic output market and a competitive factor market; the labour market. The representative finished good firm converts goods obtained from the intermediate goods firm into final good in a competitive market. This job can be delegated to household which will do cost minimisation without changing the main dynamics of the model.

The representative household maximises discounted present value of life time utility. Habit formation is introduced in their preferences to get a New Keynesian IS curve that is partially backward and partially forward looking as in Fuhrer (2000). The latter found embedding habit formation in consumption improved responses of both consumption and inflation to monetary policy. It also helps us in getting the desired hump shaped response of output and consumption to innovations in shocks which have been widely documented with data in structural vector autoregressive models. The observed increase in saving in growing economies also justifies habit persistence in consumption.

\footnotetext{
${ }^{4}$ The coefficients estimated with EME data are expected, however, to capture aspects of duality and openness as in Goyal (2011). Their values approach those of the advanced economy as the informal sector disappears. These structural aspects help account for the difference in estimated responses to shocks in the two economies.
} 
Partial indexation of nominal goods prices set by intermediate goods producing firms ensures that the model's version of the New Keynesian Phillips curve is partially backward and partially forward looking. Goyal and Tripathi (2015) provide evidence that price setting is partially backward looking in India. The central bank conducts monetary policy according to a modified Taylor (1993) rule for setting the nominal interest rate.

\subsection{Households}

The representative household enters period $t$ holding $M_{t-1}$ and $B_{t-1}$ units of money and one-period bonds respectively. In addition to this endowment, the household receives a lump sum transfer $T_{t}$ from the monetary authority at the end of the period. During period $t$ households supplies $L_{t}(i)$ units of labour to each intermediate good producing firm indexed over $i \in[0,1]$ for a total of:

$$
L_{t}=\int_{0}^{1} L_{t}(i) d i
$$

during period $t$. The household gets paid at the nominal wage $W_{t}$. At the end of period $t$, the household receives nominal profits $D_{t}(i)$ from each intermediate goods-producing firm for a total of:

$$
D_{t}=\int_{0}^{1} D_{t}(i) d i
$$

The household carries the $M_{t}$ amount of money and $B_{t}$ amount of bond to the next period. The budget constraint of the household for each period tis given by:

$$
\frac{M_{t-1}+B_{t-1}+T_{t}+W_{t} L_{t}+D_{t}}{P_{t}} \geq C_{t}+\frac{B_{t} / r_{t}+M_{t}}{P_{t}}
$$

In addition, we impose a no-Ponzi-game condition to prevent the household from excessive borrowing. Given these constraints, the household maximises the stream of their life time utility given by:

$$
E_{t} \sum_{t=0}^{t=\infty} \beta^{t} a_{t}\left[\log \left(C_{t}-\gamma C_{t-1}\right)+\log \left(M_{t} / P_{t}\right)-L_{t}\right]
$$

Where $0<\beta<1$ is the discount factor. The utility function contains a preference shock $a_{t}$, which follows a stationary autoregressive process given by:

$$
\log \left(a_{t}\right)=\rho_{a} \log \left(a_{t-1}\right)+\epsilon_{a, t} \quad 0 \leq \rho_{a}<1 \quad \epsilon_{a, t} \sim N\left(0, \sigma_{a}^{2}\right)
$$

$\epsilon_{a, t}$ is normally distributed with standard deviations $\sigma_{a}{ }^{5}$. Additively separable utility in consumption, real balances and hours worked gives a conventional specification for the IS curve which does

\footnotetext{
${ }^{5}$ The autoregressive process for $a_{t}$ implies that in steady state $\log (a)=\rho_{a} \log (a)$ and if $\rho_{a} \neq 0$, we have $\log (a)=0 \Longrightarrow$ steady state $a=1$.
} 
not include hours worked or real money balances as shown by Ireland (2001). Given this additive separability, the logarithmic specification for preferences over consumption is necessary for the model to be consistent with balanced growth.

\subsection{Firms}

\subsubsection{Final Good Producer}

The final good is produced by a firm in a perfectly competitive market, which combines the intermediate goods using the constant returns to scale technology given by:

$$
Y_{t} \leq\left[\int_{0}^{1} Y_{t}(i)^{\left(\theta_{t}-1\right) / \theta_{t}} d i\right]^{\theta_{t} /\left(\theta_{t}-1\right)}
$$

Where $\theta_{t}$ is the elasticity of substitution between intermediate goods $Y_{t}(i)$ with given price $P_{t}(i)$. In equilibrium, $\theta_{t}$ translates into a random shock to the intermediate goods-producing firms' desired markup of price over marginal cost and therefore acts like a cost-push shock in the new Keynesian traditions (Clarida, Gali, and Gertler, 1999). The final good producer firm problem is to minimise the cost (7) (it can be also done using profit maximisation) by choosing $Y_{t}(i)$ for $t=0,1,2, \ldots$ and $i \in[0,1]$ subject to the constraint given by (6):

$$
E=\int_{0}^{1} P_{t}(i) Y_{t}(i) d i
$$

Solution of the above problem leads to the following demand conditions for intermediate goods by final goods producing firms for all $i$ and $t$ :

$$
Y_{t}(i)=\left[\frac{P_{t}(i)}{P_{t}}\right]^{-\theta_{t}} Y_{t}
$$

Where the zero profit competitive aggregate price $P_{t}$ is given by:

$$
P_{t}=\left[\int_{0}^{1} P_{t}(i)^{1-\theta_{t}} d i\right]^{1 /\left(1-\theta_{t}\right)}
$$

And $\theta_{t}$ follows a stationary autoregressive process as given by ${ }^{6}$ :

$$
\log \left(\theta_{t}\right)=\left(1-\rho_{\theta}\right) \log (\theta)+\rho_{\theta} \log \left(\theta_{t-1}\right)+\epsilon_{\theta, t} \quad 0 \leq \rho_{\theta}<1 \quad \epsilon_{\theta, t} \sim N\left(0, \sigma_{\theta}^{2}\right)
$$

\subsubsection{Intermediate Goods Producers}

Each intermediate good is produced by monopolistically competitive firms according to a constant returns to scale technology by hiring $L_{t}(i)$ amount of labour from the representative household given the production technology:

$$
Y_{t}(i) \leq Z_{t} L_{t}(i)
$$

\footnotetext{
${ }^{6}$ In steady state $\theta$ and $\log (\theta)$ are constant.
} 
$Z_{t}$ is the technological progress with unit root and follows an random walk with drift given by:

$$
\log \left(Z_{t}\right)=\log (z)+\log \left(Z_{t-1}\right)+\epsilon_{z, t} \quad \epsilon_{z, t} \sim N\left(0, \sigma_{z}^{2}\right)
$$

Although each firm $i$ enjoys some market power on its own output, it is assumed to act as a price taker in the factor market and pays competitive wage as explained above. Furthermore, the adjustment of its nominal price $P_{t}(i)$ is assumed to be costly, where the cost function is convex in the size of the price adjustment. Following Rotemberg $(1982,1987)$, these quadratic adjustments costs are defined as:

$$
\frac{\varphi_{p}}{2}\left[\frac{P_{t}(i)}{\pi_{t-1}^{\alpha} \pi^{1-\alpha} P_{t-1}(i)}-1\right]^{2} Y_{t}
$$

Where $\varphi_{p}>0$ is the price adjustment cost and $\pi$ represents the steady rate of inflation being targeted by the central bank with $0 \leq \alpha \leq 1$. Extent of backward and forward looking inflation depends upon $\alpha$. When $\alpha=0$, then price setting is purely-forward looking and for $\alpha=1$ price setting is purely backward-looking. This specification leads to partial indexation when $0<\alpha<1$ implying that some prices are set in a backward looking manner. The firm maximises its present market value given by:

$$
E \sum_{t=0}^{\infty} \beta^{t} \lambda_{t}\left[\frac{D_{t}(i)}{P_{t}}\right]
$$

The real market value is present discounted value of utility that these firms can provide to the household through the distribution of dividend. Lagrange multiplier of the household's optimisation, $\lambda_{t}$, represent the marginal utility of one unit of profit. A firm's profit distributed as dividend to the household is given by:

$$
\frac{D_{t}(i)}{P_{t}}=\frac{P_{t}(i)}{P_{t}} Y_{t}(i)-\frac{W_{t} L_{t}(i)}{P_{t}}-\frac{\varphi_{p}}{2}\left[\frac{P_{t}(i)}{\pi_{t-1}^{\alpha} \pi^{1-\alpha} P_{t-1}(i)}-1\right]^{2} Y_{t}
$$

Using the demand derived from the final good producer the dividend can be written as:

$$
\frac{D_{t}(i)}{P_{t}}=\left[\frac{P_{t}(i)}{P_{t}}\right]^{1-\theta_{t}} Y_{t}-\frac{W_{t} L_{t}(i)}{P_{t}}-\frac{\varphi_{p}}{2}\left[\frac{P_{t}(i)}{\pi_{t-1}^{\alpha} \pi^{1-\alpha} P_{t-1}(i)}-1\right]^{2} Y_{t}
$$

\subsection{Monetary Authority}

Monetary policy is represented by a generalised Taylor (1993) rule of the form:

$$
\log \left(\frac{r_{t}}{r_{t-1}}\right)=\rho_{\pi} \log \left(\frac{\pi_{t}}{\pi}\right)++\rho_{g} \log \left(\frac{g_{t}}{g}\right)+\epsilon_{r, t} \quad \epsilon_{r, t} \sim N\left(0, \sigma_{r}^{2}\right)
$$

Central bank responds to deviation of inflation $\left(\pi_{t}\right)$ and growth $\left(g_{t}\right)$ from their respective steady state values; $\pi$ denotes the rate of inflation being targeted by the central bank. Having change in interest rate instead of level of rate on the left hand side in (13) allows for interest rate smoothening. Fuhrer and Moore (1995) have also used a similar specification and it is especially suitable when the 
central bank and agents have imperfect information about the economy. The above specification leads to unique dynamically stable rational expectation solutions when $\rho_{\pi}$ and $\rho_{g}$ lie between 0 and 1. We impose this restrictions while maximising the likelihood.

\subsection{Planner's Problem}

It is important to have some reference level of output compared to which we can analyze deviations due to different shocks. Therefore we define a level of output, which a benevolent social planner who can get rid of the nominal rigidity, can achieve. In our model we have one nominal rigidity due to the cost of price adjustment. Aggregate resource constraint of the economy when there is no nominal rigidity is given by:

$$
C_{t}=Y_{t}
$$

The above resource constraint basically leads to output being equals to consumption. The social planner maximises a social welfare function based on representative household's utility in the absence of nominal rigidities. See Vetlov et al. (2011) for a discussion on potential output in DSGE models. Based on this capacity output is defined as $\left(Q_{t}\right)$, obtained by solving the planner's problem who maximises:

$$
E_{t} \sum_{t=0}^{t=\infty} \beta^{t} a_{t}\left[\log \left(Q_{t}-\gamma Q_{t-1}\right)-\int_{0}^{1} L_{t}(i) d i\right]
$$

Subject to:

$$
Q_{t} \leq Z_{t}\left[\int_{0}^{1} L_{t}(i)^{\left(\theta_{t}-1\right) / \theta_{t}} d i\right]^{\theta_{t} /\left(\theta_{t}-1\right)}
$$

The above constraint is the consequence of the first order conditions for the intermediate good producer, which gives $Y_{t}(i)=Z_{t} L_{t}(i)$ and using this first order condition in the objective function of the final good producer, one can get the above constraint. The output gap is the ratio of actual output $Y_{t}$ to capacity output $Q_{t}{ }^{7}$.

\section{Types of Shocks}

\subsection{Baseline}

In our baseline model the production function is given by (10) and technological progress is given by (11). Since the technology progress has an unit root we make variables stationary by deflating

\footnotetext{
${ }^{7}$ The above model has no investment. But that doesn't mean investment is constant. As argued by Woodford (2003) as long we are not calibrating inter-temporal elasticity of substitution with inter-temporal elasticity of substitution of non durable consumer expenditure, investment is not treated as constant in these models. One should treat inter-temporal elasticity of substitution as obtained from overall inter-temporal elasticity of substitution including the private investment expenditure (see Woodford (2003) page 243 and 352). Since we estimate the model parameters, therefore not including capital does not pose a serious concern for the model.
} 
with the technological progress and linearising the model around the steady state. The linearised model is given in Appendix A. For details of the derivation see Goyal and Kumar (2017). Linearised technology shock process is given by (equation E.3 in Appendix A):

$$
\hat{z}_{t}=\epsilon_{z, t}
$$

\subsection{News Shocks}

We augment our baseline model with anticipated shocks in technology, interest rate and markup following Grohe and Uribe (2012). With anticipated technology shocks equation E.3 can be written as:

$$
\hat{z}_{t}=\epsilon_{z, t}+n z_{t-i}^{i}
$$

Where $n z^{i}$ is the technology shock anticipated $i$ periods before (news). This formalisation of TFP as the sum of two components, one capturing the contemporaneous shocks to productivity and the other capturing the slow diffusion of new technology, receives empirical support form a host of microeconomic evidence (e.g. Rotemberg, 2003 and references therein). Similarly in case of anticipated markup and interest rate shock: equation E.2 and E.10 in Appendix A can be written as:

$$
\begin{gathered}
\hat{\Theta}_{t}=\rho_{\Theta} \hat{\Theta}_{t-1}+\epsilon_{\Theta, t}+n \Theta_{t-j}^{j} \\
\hat{r}_{t}=\hat{r}_{t-1}+\rho_{\pi} \hat{\pi}_{t}+\rho_{g} \hat{g}_{t}+\epsilon_{r, t}+n r_{t-j}^{j}
\end{gathered}
$$

Where $n r_{t-j}^{j}$ and $n \Theta_{t-j}^{j}$ are the interest rate and markup shock anticipated $j$ periods before and realised in period $t$. Each of these shocks come from a different distribution.

\subsection{Correlated News Shocks}

News shocks in Grohe and Uribe (2012) are i.i.d and comes from a different distribution. Walker and Leeper (2011) argue that compared to these news shocks, another kind of news shocks, which they call correlated news allows models to generate hump-shaped response functions with far less reliance on real rigidities such as habit persistence. Their correlated news shocks comes from same distribution and also helps in mitigating one of the drawback of news shock in Grohe and Uribe (2012) known as "comovement problem" in literature as documented by Cochrane (1994) and recently studied by Jaimovich and Rebelo (2009) and Grohe and Uribe (2012). It is the tendency for news about technological improvements to generate an economic downturn in the period before the improved technology is realised.

With anticipated technology shock equation E.3 in Appendix A now becomes: 


$$
\hat{z}_{t}=\phi_{0} \epsilon_{z, t}+\phi_{1} \epsilon_{z, t-1}
$$

Similarly in case of anticipated markup and interest rate shocks, equations E.2 and E.10 in Appendix A can be written as:

$$
\begin{gathered}
\hat{\Theta}_{t}=\rho_{\Theta} \hat{\Theta}_{t-1}+\phi_{0} \epsilon_{\Theta, t}+\phi_{1} \epsilon_{\Theta, t-1} \\
\hat{r}_{t}=\hat{r}_{t-1}+\rho_{\pi} \hat{\pi}_{t}+\rho_{g} \hat{g}_{t}+\phi_{0} \epsilon_{r, t}+\phi_{1} \epsilon_{r, t-1}
\end{gathered}
$$

Where $\sum_{i=0}^{i=1} \phi_{i}=1$

\subsection{Imperfect Information}

Each intermediate good is produced by a monopolistically competitive firm according to a constant returns to scale technology by hiring $L_{t}(i)$ amount of labour from the representative household given the production technology:

$$
Y_{t}(i) \leq Z_{t} L_{t}(i)
$$

$Z_{t}$ is the technological progress which we take as in Blanchard et al. (2013) ${ }^{8}$.

$$
\begin{gathered}
Z_{t}=\Gamma^{t} e^{p_{t}} \\
p_{t}=x_{t}+s_{t}
\end{gathered}
$$

The permanent component, $x_{t}$, follows a unit root process given by

$$
\Delta x_{t}=\rho_{x} \Delta x_{t-1}+\epsilon_{x, t} \quad \epsilon_{x, t} \sim N\left(0, \sigma_{x}^{2}\right)
$$

The transitory component, $s_{t}$, follows a stationary process given by

$$
s_{t}=\rho_{s} s_{t-1}+\epsilon_{s, t} \quad 0 \leq \rho<1 \quad \epsilon_{s, t} \sim N\left(0, \sigma_{s}^{2}\right)
$$

We have $p_{t}$ as random walk

$$
p_{t}=p_{t-1}+u_{t} \quad u_{t} \sim N\left(0, \sigma_{u}^{2}\right)
$$

As shown in Quah $(1990,1991)$, any univariate process has infinite number of decomposition between permanent and transitory components with orthogonal innovations. There is one process which satisfies above description of permanent and temporary component and is given by

${ }^{8} Z_{t}=\Gamma^{t} e^{p_{t}} \Longrightarrow \log \left(Z_{t}\right)=\log \left(\Gamma^{t}\right)+p_{t}$. We have $\log \left(\frac{Z_{t}}{Z_{t-1}}\right)=\log (\Gamma)+\Delta p_{t}$. Let's call $\frac{Z_{t}}{Z_{t-1}}=z_{t}$ and we have steady state $z=\Gamma$ 


$$
\begin{gathered}
\rho_{x}=\rho_{s}=\rho \\
\sigma_{x}^{2}=(1-\rho)^{2} \sigma_{u}^{2} \quad \sigma_{s}^{2}=\rho \sigma_{u}^{2}
\end{gathered}
$$

In case of perfect information households know both permanent and transitory components of $p_{t}$ while in case of imperfect information household's don't know the components of $p_{t}$, they just observe $p_{t}$. They hear a noisy signal for permanent component $x_{t}$ given by:

$$
q_{t}=x_{t}+v_{t} \quad v_{t} \sim N\left(0, \sigma_{v}^{2}\right)
$$

Observation Equation

$$
\begin{gathered}
p_{t}=x_{t}+s_{t} \\
q_{t}=x_{t}+v_{t} \quad v_{t} \sim N\left(0, \sigma_{v}^{2}\right)
\end{gathered}
$$

State Equation

$$
\begin{gathered}
x_{t}=(1+\rho) x_{t-1}-\rho x_{t-2}+\epsilon_{x, t} \quad \epsilon_{x, t} \sim N\left(0, \sigma_{x}^{2}\right) \\
s_{t}=\rho s_{t-1}+\epsilon_{s, t} \quad \epsilon_{s t} \sim N\left(0, \sigma_{s}^{2}\right)
\end{gathered}
$$

We want to write this as

$$
\begin{gathered}
X_{t}=A X_{t-1}+B e_{t} \\
Y_{t}=C X_{t}+D e_{t}
\end{gathered}
$$

Where $X_{t}=\left(x_{t}, x_{t-1}, s_{t}\right)^{\prime}$ and $Y_{t}=\left(p_{t}, q_{t}\right)^{\prime}$ and $e_{t}=\left(\epsilon_{x, t}, \epsilon_{s, t}, v_{t}\right)^{\prime}$. One can write the matrices $\mathrm{A}$, $\mathrm{B}, \mathrm{C}$ and $\mathrm{D}$ as given below:

$$
A=\left[\begin{array}{ccc}
1+\rho & -\rho & 0 \\
1 & 0 & 0 \\
0 & 0 & \rho
\end{array}\right] \quad B=\left[\begin{array}{lll}
1 & 0 & 0 \\
0 & 0 & 0 \\
0 & 1 & 0
\end{array}\right] \quad C=\left[\begin{array}{lll}
1 & 0 & 1 \\
1 & 0 & 0
\end{array}\right] \quad D=\left[\begin{array}{lll}
0 & 0 & 0 \\
0 & 0 & 1
\end{array}\right]
$$

And variance covariance matrices can be written as:

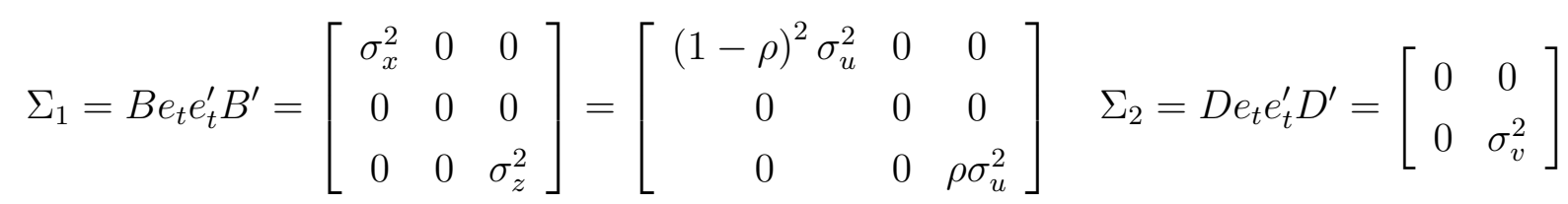


From Kalman recursion one can derive updated covariance matrix as:

$$
\begin{gathered}
P_{t \mid t}=P_{t \mid t-1}-\left(P_{t \mid t-1} C^{\prime}\right)\left(C P_{t \mid t-1} C^{\prime}+\Sigma_{2}\right)^{-1}\left(C P_{t \mid t-1}\right) \\
P_{t+1 \mid t}=A\left(P_{t \mid t-1}-\left(P_{t \mid t-1} C^{\prime}\right)\left(C P_{t \mid t-1} C^{\prime}+\Sigma_{2}\right)^{-1}\left(C P_{t \mid t-1}\right)\right) A^{\prime}+\Sigma_{1}
\end{gathered}
$$

We use steady state Kalman filter. The Kalman filter explained above is in steady state if the error covariance matrix is time invariant. This implies

$$
\begin{gathered}
P_{t+1 \mid t}=P_{t \mid t-1}=P \\
P=A\left(P-P C^{\prime}\left(C P C^{\prime}+\Sigma_{2}\right)^{-1} C P\right) A^{\prime}+\Sigma_{1}
\end{gathered}
$$

One can solve for $P$ and define steady state Kalman gain as

$$
K=P C^{\prime}\left(C P C^{\prime}+\Sigma_{2}\right)^{-1}
$$

Updated state variables can be written as:

$$
X_{t \mid t}=X_{t \mid t-1}+P_{t \mid t-1} C^{\prime}\left(C P_{t \mid t-1} C^{\prime}+\Sigma_{2}\right)^{-1}\left(y_{t}-C X_{t \mid t-1}\right)
$$

Using steady state Kalman gain one can write

$$
\begin{gathered}
X_{t \mid t}=X_{t \mid t-1}+K\left(y_{t}-C X_{t \mid t-1}\right) \\
X_{t \mid t}=A X_{t-\mid t-1}+K\left(y_{t}-C A X_{t-1 \mid t-1}\right) \\
X_{t \mid t}=A X_{t-\mid t-1}-K C A X_{t-1 \mid t-1}+K y_{t} \\
X_{t \mid t}=(I-K C) A X_{t-1 \mid t-1}+K y_{t}
\end{gathered}
$$

Equivalent Full Information Model

$$
\begin{gathered}
X_{t \mid t}=A X_{t-\mid t-1}+K\left(y_{t}-C A X_{t-1 \mid t-1}\right) \\
y_{t}=C A X_{t-1 \mid t-1}+y_{t}-C A X_{t-1 \mid t-1}
\end{gathered}
$$

Identify $X_{t}$ with $X_{t \mid t}$ and $\epsilon_{t}$ with $y_{t}-C A X_{t-1 \mid t-1}$

$$
X_{t}=A X_{t-1}+K \epsilon_{t}
$$




$$
\begin{gathered}
y_{t}=C A X_{t-1}+\epsilon_{t} \\
\epsilon_{t}=y_{t}-C A X_{t-1 \mid t-1} \Longrightarrow y_{t}-C X_{t \mid t-1} \Longrightarrow C X_{t}+D e_{t}-C X_{t \mid t-1} \Longrightarrow C\left(X_{t}-X_{t \mid t-1}\right)+D e_{t} \\
E\left(\epsilon_{t} \epsilon_{t}^{\prime}\right)=C P_{t \mid t-1} C^{\prime}+\Sigma_{2}
\end{gathered}
$$

Steady state value can be obtained by $C P C^{\prime}+\Sigma_{2}$. One can always find a matrix $G$ such that steady state value of $E\left(\epsilon_{t} \epsilon_{t}^{\prime}\right)=C P C^{\prime}+\Sigma_{2}=E\left(G \nu_{t} \nu_{t}^{\prime} G^{\prime}\right)=G G^{\prime}$, where $\nu$ represents standard i.i.d. normal and thus above equation can be written as.

$$
\begin{gathered}
X_{t}=A X_{t-1}+K G \nu_{t} \\
y_{t}=C A X_{t-1}+G \nu_{t}
\end{gathered}
$$

Since we identify $X_{t}$ with $X_{t \mid t}$ and $\epsilon_{t}$ with $y_{t}-C A X_{t-1 \mid t-1}$ and agents observe both of these variables and thus the above equation is observationally equivalent to the original signal extraction model.

\section{Data}

We estimate the model using quarter-to-quarter change in the natural logarithm of real GDP9,10, quarter-to-quarter changes in the natural logarithm of consumer price index and short-term nominal interest rate i.e. 15-91 days Treasury bill rate, converted to a quarterly yields in line with the corresponding variable in the theoretical model for 1996Q2 to 2015 Q4 ${ }^{11}$. Apart from this, we also use a stock market variable (stock price index, price earning ratio or market to book value ratio of Bombay Stock Exchange benchmark index, BSE Sensex) for estimating regression equations in section 2. The figures for real Gross domestic product and consumer price index are seasonally adjusted using $\mathrm{X}$-13 ARIMA. Interest rate was not seasonally adjusted.

\footnotetext{
${ }^{9}$ Ideally it should be in per capita terms, but since we couldn't find any source for quarterly data on working population and we used the growth rate only.

${ }^{10}$ There is an issue in creating continuous series for the national accounts variable as we have data from three base years (1999-00, 2004-05 and 2011-12) to compile to create a uniform series. The linking procedures commonly used in the literature generally involve the backward extrapolation of the most recent available series using the growth rates of older series called retropolation or interpolation between the benchmark years of successive series (Fuente, 2009). We use retropolation as it suits our interest and is very simple. Suppose we have two series for a economic variable of interest. We calculate the log difference between the old and new series (when the new series starts and we have data for both series) and add this difference to old series to create a uniform series thus preserving the growth rate of the old series. The implicit assumption is that the "error" contained in the older series remains constant over time that is, that it already existed at time 0 and that its magnitude, measured in proportional terms, has not changed between 0 and the time new series starts.

${ }^{11}$ Garcia-Cicco et al. (2009), criticise using short quarterly data particularly due to the inability to characterise non-stationary shocks using a short span of data. But we are limited by the availability of the quarterly data set.
} 


\section{Results and Analysis}

\subsection{Parameter Estimates}

We estimate the models using quarterly gross domestic product growth rate, consumer price inflation and quarterly treasury bills rate. We need to match the data with the model and same is explained in Appendix B. Steady-state values of output growth, inflation, and the short-term interest rate in the model are given by $z=g, r=\frac{\pi z}{\beta}=\frac{\pi g}{\beta}$. Hence $z=g=1.0169 \pi=1.0170 r=1.0181$, see Goyal and Kumar (2017). This suggest a value of $\beta>1$ using the steady state relation $r=\frac{\pi z}{\beta}$. This is the well known Weil's (1989) risk-free rate puzzle, according to which representative agent models like the one used here systematically over predict interest rate. So we calibrate $\beta=0.999$. Once we fixed it $r$ is no more free and is calculated using steady state relations (see Appendix B). We also fix $\Psi$ as 0.10 as explained in Ireland (2004). This is similar to fixing the Calvo parameter to such value that it implies that each individual good's price remains fixed, on average, for 3.7 quarters, that is, for a bit less than one year. Goyal and Tripathi (2015) also provide evidence that an average Indian firm changes prices about once in a year.

Baseline estimates of the model are given in Table 4 in Appendix $C^{12}$. Table 5 in Appendix $C$ gives the log likelihood of models estimated with news in technology, markup and interest rate shocks as Grohe and Uribe (2012). News in technology shocks at longer horizon increases likelihood marginally. News in markup shock is not supported by the data. There is clear evidence of significant amount of news element in the interest rate. We select the model with 8 period anticipation horizon for technology shock and one period anticipation horizon for both interest rate and markup shock. Estimated parameters with anticipated news in technology, interest rate and markup shocks are given in tables 7 and 8 in Appendix $\mathrm{C}^{13}$. Bringing anticipated technology shock (news) reduces the variance of the instantaneous technology shock (noise) whereas other parameters remain the same. Bringing anticipated interest rate shock (news) reduces the variance of the instantaneous interest rate shock (noise). There is not so much difference between other parameters. Bringing anticipated markup shock (news) does not change parameter estimates for all anticipation horizons and for each horizon the variance of anticipated markup shock is zero. It is also evident that bringing anticipated interest rate shock increases the likelihood of the model and in terms of model fit one can argue that the news shock in interest rate are important in Indian business cycle fluctuations.

Tables 12 and 13 in Appendix $C$ gives the estimated parameters for the model with correlated technology, interest rate and markup shock as in Walker and Leeper (2011). Although correlated news in technology does not improves the model fit but correlated interest rate and markup shock

\footnotetext{
${ }^{12}$ Goyal and Kumar (2017) report slightly different parameters obtained using FMINUNC. These parameters have been obtained using Dynare implementation of CSMINWEL and impulse responses have been calculated based on the parameters estimated using Dynare. Goyal and Kumar (2017) reports standard error from bootstrap simulations. These standard errors are reported by Dynare.

${ }^{13}$ We also estimate a model with $\hat{z_{t}}=\epsilon_{z, t}+n z_{t-4}^{4}+n z_{t-8}^{8}$ as estimated by Grohe and Uribe (2012) but the likelihood of that model is also less than the model with $\hat{z}_{t}=\epsilon_{z, t}+n z_{t-1}^{1}$.
} 
significantly improves the model fit. Table 17 in Appendix $C$ gives the parameter estimates with unit root technology as in case of Blanchard et al. (2013) with imperfect information ${ }^{14}$. There is not so much difference in the parameters in comparison to the baseline but the estimates suggest that standard deviation of noise shock $\sigma_{s}$ is significant.

\subsection{Impulse Responses}

We have two demand shocks in the model, preference and monetary policy shocks and two supply shocks markup and technology in our baseline specification. Demand shocks move output and inflation in the same direction whereas supply shocks move them in opposite direction (Figure 4 in Appendix C).

News in technology at horizon eight, changes the impulse response in significant ways (Figure 5 Appendix C). Anticipation at eight period leads to zero variance in surprise technology shock and the entire variance is attributed to news shock. At anticipation horizon one, the variance of news in technology shock is estimated to be zero and the entire variance is attributed to surprise shock as in (Figure 6 Appendix C). It is clear that technology shock is anticipated at long horizon, the anticipation at the short horizon could be difficult if their is significant amount of uncertainty prevailing for the technology shock at shorter duration.

News in interest rate doesn't affect the response of output, inflation, interest rate to markup shock. The variance of interest rate shock (surprise) decreases slightly as we can see from Figure 7 Appendix C. Anticipated interest rate shock (news) has a significant impact on output and inflation. The response of output to technology shock increases and the response of inflation remains the same. Response of output and interest rate due to preference shock decreases but the impact on inflation remains same. News in interest rate diminishes the role of preference shocks and makes technology shocsk slightly more important for determination of output. News in markup does not change impulse responses and there is no effect of news in markup as the estimated variance is 0 (Figure 8 Appendix $C$ ).

There is evidence that correlated technology does not affect the impulse response significantly (Figure 9 Appendix C). But correlated interest rate shocks make monetary transmission even stronger (Figure 10 Appendix C). There is evidence of correlated shocks and they make adverse monetary shocks persistent. The affect of technology shock on interest rate becomes sharp. Correlated markup shock makes interest rate transmission stronger, sharpens the response of interest rate to technology shock and decreases the response of output and inflation to preference shock (Figure 11 Appendix C).

Learning about the trend component of technology progress suggest that there is significant noise in permanent component of technological progress. Now we have six shocks in the model.

\footnotetext{
${ }^{14}$ We attempt pure likelihood estimation but estimates remain very sensitive to initial values and therefore we do bayesian estimation in Dynare. We choose priors based on literature and the estimates obtained in this paper.
} 
Responses of three shocks, preference, markup and interest rate does not change significantly as given in Figure 13 of Appendix C. Now the technology shock has been decomposed in three components, permanent, temporary and noise and is given Figure 12 of Appendix C. A significant portion of the impact of technology shock is transferred to the temporary component of the technology shock as well as to the noise shock.

\subsection{Forecast Error Variance Decomposition}

Forecast error variance decomposition of output, inflation and interest rate for the baseline model is given in Table 6 in Appendix C. Movement in output growth is driven primarily by a combination of preference and monetary policy shocks. This implies that output is mainly demand driven. Movement in inflation is mainly due to markup shock and interest rate shock, suggesting that inflation is mainly supply side driven but leads to excessive response of interest rate. Movement in interest rate is mainly due to preference shock but interest rate shock also plays an important role especially at higher frequencies.

Anticipated technology shock as in Grohe and Uribe (2012) does not change forecast error variance decomposition significantly as given in Table 9 Appendix C. Anticipated interest rate shock (news) makes monetary policy more important for output determination (Table 10 Appendix C). The contribution of unanticipated interest rate shock (noise) remains the same but around 10 percent of the output variance is explained by the news component. Share of preference shock in explaining output variance decreases. Movement in inflation is still mainly due to markup shock and monetary policy shock and news shock explains about one third of the variance of inflation (both news and surprise). Movement in interest rate is mainly due to preference shock and markup shock also plays an important role especially at higher frequencies. There is also evidence that significant amount of variation in interest rate is anticipated as news shock explains around 15 percent of the variation in interest rate. Anticipated markup shock does not change forecast error variance decomposition significantly as given in Table 11 Appendix C.

Correlated technology shock as in Walker and Leeper (2011) does not change forecast error variance decomposition significantly in comparison to the baseline model as given in Table 14 Appendix C. Correlated interest rate and markup shock as in Walker and Leeper (2011) changes forecast error variance decomposition significantly in comparison to the baseline model as given in tables 15 and 16 Appendix C. Interest rate shocks becomes more important for output determination. Share of preference shock in explaining output variance decreases.

Decomposing technology shocks as in Blanchard et al. (2013) into permanent, temporary and noise produces the forecast error variance decomposition given in Table 18 in Appendix C. The share of output variance explained by technology shock increases. At smaller frequencies, temporary shocks are as important as permanent shocks whereas at higher frequency permanent shocks become predominant. Therefore, decomposing technology shock into permanent and temporary and bringing 
uncertainty increases the share of output variance explained by technology shock, partially resolving the low share of technology shocks (in explaining the variation of output) found in Goyal and Kumar (2017). The low share of technology shocks (in explaining the variation of output) found in Goyal and Kumar (2017) could be partly due to the uncertainty prevailing about the technological progress in emerging economies like India and once we take that uncertainty in account, the share increases. Share of output variance due to interest rate shock decreases. Noise shock does not explain significant variance of any variable.

\section{Conclusion}

Results suggest that anticipated interest rate shocks (news) as in Grohe and Uribe (2012) are important for business cycles in India. Out of total variance explained by interest rate shocks, one third is due to anticipated interest rate shocks. There is also evidence that significant portion of the interest rate movement is anticipated in advance. Adding a moving average term in the technology shock process as in Walker and Leeper (2011) does not significantly change the fit of the model but a moving average term in interest rate and markup significantly affects the fit of the model and makes monetary transmission stronger. There is evidence of low persistence of markup shock (our estimates of $\rho_{\Theta}$ are very low and is not significant in case of most of models being estimated) and data prefers a model with moving average term in the markup shock process ${ }^{15}$. If correlation in markup shocks is introduced it implies higher inflation in current period leads to higher inflation next period. Since the central bank is responding to inflation, higher inflation next period leads to expectation of higher interest rate next period, thus increasing the impact of interest rate anticipation. Interest rate shocks explain a large portion of output fluctuation and the shock has higher variance compared to developed economies like US (see Goyal and Kumar (2017)).

Goyal and Kumar (2017) find a lower impact of technology shock in output in Indian business cycles. Bringing anticipated technology shock also does not change that conclusion significantly. But with imperfect knowledge of permanent component of technology shock its contribution to output rises although it is still below US levels of 45. Technological progress has a higher permanent or catch-up component in emerging markets. It also affects the cost side more so interest rate falls in India compared to a rise in the US in response to a positive technology shock. The higher uncertainty of the permanent component may be reducing consumer demand response to a rise in supply and incomes that is a feature of advanced economies.

\footnotetext{
${ }^{15} \mathrm{~A}$ zero mean $\mathrm{AR}(1)$ process can be written as $y_{t}=\rho y_{t-1}+e_{t}$. In stationary case the varince of $y$ is given by $\frac{\sigma_{e}^{2}}{(1-\rho)^{2}}$. Correlation at any lag $h$ is given by $\rho^{h}$ for $h=1,2,3$.. The high value of $\rho$ implies persistence shock as the correlation remains high at higher lags too. $\mathrm{A} \mathrm{MA}(1)$ process is given by $y_{t}=e_{t}+\theta e_{t-1}$. Now the variance of $y$ is given by $\sigma_{e}^{2}\left(1+\theta^{2}\right)$. Correlation at lag 1 is given by $\frac{\theta}{1+\theta^{2}}$ and it is zero for any other higher lag. Since $e_{t}$ is white noise $E\left(Y_{t} Y_{t-s}\right) \neq 0$ for $s=1$ only. Therefore shock to a $\operatorname{AR}(1)$ process is going to have more persistent effect in comparison to a MA(1) process keeping other things constant. Our markup shock process are not found to be persistent as $A R(1)$ coefficient is small and insignificant in most of estimations although it is correlated at lag 1 because of the significant MA (1) coefficient.
} 
These results have implications for monetary policy in emerging economies like India. Since anticipated interest rates matter, better policy communication would improve monetary transmission. Reducing the short-term variance in interest rate shock in response to volatile markup shocks, especially since they are not persistent, would decrease output growth variability. It would also reduce the crowding out of technology driven rise in potential output due to monetary over-reaction. Consumer aggregate demand does not respond adequately to uncertain potential output expansion in an emerging market, so it needs to be nurtured. Government supply-side reforms that remove bottlenecks and reduce the excess volatility of mark-up shocks are also required. 


\section{References}

[1] Aguiar, M. and Gopinath, G., 2007. Emerging market business cycles: The cycle is the trend. Journal of Political Economy, 115(1), pp.69-102.

[2] Beaudry, P. and Lucke, B., 2010. Letting different views about business cycles compete. NBER Macroeconomics Annual, 24(1), pp.413-456.

[3] Blanchard, O.J., L'Huillier, J.P. and Lorenzoni, G., 2013. News, noise, and fluctuations: An empirical exploration. The American Economic Review, 103(7), pp.3045-3070.

[4] Boz, E., Daude, C. and Durdu, C.B., 2011. Emerging market business cycles: Learning about the trend. Journal of Monetary Economics, 58(6), pp.616-631.

[5] Carroll, C.D., Overland, J. and Weil, D.N., 2000. Saving and growth with habit formation. American Economic Review, pp.341-355.

[6] Clarida, R., Gali, J. and Gertler, M., 1999. The science of monetary policy: a New Keynesian perspective (No. w7147). National Bureau of Economic Research.

[7] Cochrane, J.H., 1994. Shocks. Carnegie-Rochester conference series on Public Policy 41.

[8] De la Fuente Moreno, À., 2014. A "mixed" splicing procedure for economic time series. Estadística Española, 56(183), pp.107-121.

[9] Fuhrer, J. and Moore, G., 1995. Inflation persistence. The Quarterly Journal of Economics, pp.127-159.

[10] Fuhrer, J., 2000. Habit formation in consumption and its implications for monetary-policy models. American Economic Review, pp.367-390.

[11] Garcia-Cicco, J., Pancrazi, R. and Uribe, M., 2006. Real business cycles in emerging countries? (No. w12629). National Bureau of Economic Research.

[12] Gomes, S., Iskrev, N. and Mendicino, C., 2017. Monetary policy shocks: We got news!. Journal of Economic Dynamics and Control, 74, pp.108-128.

[13] Goyal, A. 2011. A general equilibrium open economy model for emerging markets: Monetary policy with a dualistic labor market. Economic Modelling, 28(2), pp.1392-1404.

[14] Goyal, A. and Kumar, A., 2017. A DSGE model-based analysis of the Indian slowdown. IGIDR Working Paper No. WP-2017-003.

[15] Goyal, A. and Pujari, A.K., 2005. Identifying long run supply curve in India. Journal of Quantitative Economics, New Series Volume 3, No. 2, pp. 1-15

[16] Goyal, A. and Tripathi, S., 2015. Separating shocks from cyclicality in Indian aggregate supply. Journal of Asian Economics, 38, pp.93-103. 
[17] Hamilton, J.D., 1994. Time series analysis: Princeton University Press.

[18] Ireland, P.N., 2004. Technology shocks in the new Keynesian model. The Review of Economics and Statistics, 86(4), pp.923-936.

[19] Ireland, P.N., 2010. A New Keynesian perspective on the great recession (No. w16420). National Bureau of Economic Research.

[20] Jaimovich, N. and Rebelo, S., 2009. Can News about the Future Drive the Business Cycle?. American Economic Review, 99(4), pp.1097-1118.

[21] Jorda, O., 2005. Estimation and inference of impulse responses by local projections. American Economic Review, 95(1), pp.161-182.

[22] Quah, D., 1990. Permanent and transitory movements in labor income: An explanation for" excess smoothness" in consumption. Journal of Political Economy, 98(3), pp.449-475.

[23] Quah, D., 1992. The relative importance of permanent and transitory components: identification and some theoretical bounds. Econometrica: Journal of the Econometric Society, pp.107-118.

[24] Rotemberg, J.J., 1982. Sticky prices in the United States. The Journal of Political Economy, pp.1187-1211.

[25] Rotemberg, J.J., 1987. The New Keynesian microfoundations. In NBER Macroeconomics Annual 1987, 2, pp.69-116. The MIT Press.

[26] Rotemberg, J.J., 2003. Stochastic Technical Progress, Smooth Trends, and Nearly Distinct Business Cycles. The American Economic Review, 93(5), pp.1543-1559.

[27] Smets, F., and Wouters, R., 2003. "An estimated dynamic stochastic general equi- librium model of the Euro Area." Journal of the European Economic Association, 1, pp.1123-1175.

[28] Schmitt-Grohé, S. and Uribe, M., 2012. What's news in business cycles. Econometrica, 80(6), pp.2733-2764.

[29] Vetlov, I., Hlédik, T., Jonsson, M., Henrik, K. and Pisani, M., 2011. Potential output in DSGE( No. 1351). European Central Bank Working Paper.

[30] Weil, P., 1989. The equity premium puzzle and the risk-free rate puzzle. Journal of Monetary Economics, 24(3), pp.401-421.

[31] Woodford, M., 2003. Interest and Prices: Foundations of a Theory of Monetary Policy. Princeton University Press.

[32] Zeev, N.B., Pappa, E. and Vicondoa, A., 2017. Emerging economies business cycles: The role of commodity terms of trade news. Journal of International Economics, 108, pp.368-376. 


\section{Appendix}

\section{A Log Linearized Version}

\section{A.1 Baseline}

First order conditions are found and symmetric equilibrium is obtained. We eliminate few redundant variables and define $y_{t}=\frac{Y_{t}}{Z_{t}}, c_{t}=\frac{C_{t}}{Z_{t}}, z_{t}=\frac{Z_{t}}{Z_{t-1}}\left(\log \left(\frac{Z_{t}}{Z_{t-1}}\right)=\log (z)+\epsilon_{z, t}\right), q_{t}=\frac{Q}{Z_{t}}$ and where normalisation by unit root technological shock makes the variables stationary compared to uppercase variables. This is required as some of the variables have unit root from the technology shock. We also define $\Omega_{t}=\lambda_{t} Z_{t}$.

Preference shock process can be linearised as:

$$
\hat{a_{t}}=\rho_{a} a_{t-1}+\epsilon_{a, t}
$$

Markup shock process can be linearised as $\left(\hat{\Theta}_{t}=-\frac{\hat{\theta}}{\varphi_{p}}\right)$ :

$$
\hat{\Theta}_{t}=\rho_{\Theta} \hat{\Theta}_{t-1}+\epsilon_{\Theta, t}
$$

Technological shock process can be linearised as:

$$
\hat{z}_{t}=\epsilon_{z, t}
$$

First order condition with respect to $C_{t}$ :

$(z-\beta \gamma)(z-\gamma) \hat{\Omega}_{t}=z \gamma \hat{y}_{t-1}-\left(z^{2}+\beta \gamma^{2}\right) \hat{y}_{t}+\beta \gamma z E_{t} \hat{y}_{t+1}+\left(z-\beta \gamma \rho_{a}\right)(z-\gamma) \hat{a}_{t}-\gamma z \hat{z}_{t}+\beta \gamma z E_{t} \hat{z}_{t+1}$

First order condition with respect to $B_{t}$ :

$$
\hat{\Omega}_{t}=E_{t} \hat{\Omega}_{t+1}+\hat{r}_{t}-E_{t} \hat{z}_{t+1}-E_{t} \hat{\pi}_{t+1}
$$

Intermediate goods producer's first order condition with respect to $P_{t}(i)$ using $\Psi=\frac{\theta-1}{\varphi_{p}}, \hat{\Theta}_{t}=-\frac{\hat{\theta}}{\varphi_{p}}$

$$
(\beta \alpha+1) \hat{\pi}_{t}=\alpha \hat{\pi}_{t-1}+\beta E_{t} \hat{\pi}_{t+1}+\Psi \hat{a}_{t}-\Psi \hat{\Omega}_{t}+\hat{\Theta}_{t}
$$

Growth rate is given by:

$$
\hat{g}_{t}=\hat{y}_{t}-\hat{y}_{t-1}+\hat{z}_{t}
$$

Potential Output is given by: 


$$
0=z \gamma \hat{q}_{t-1}-\left(z^{2}+\beta \gamma^{2}\right) \hat{q}_{t}+\beta \gamma z E_{t} \hat{q}_{t+1}+\beta \gamma(z-\gamma)\left(1-\rho_{a}\right) \hat{a}_{t}-\gamma z \hat{z}_{t}++\beta \gamma z E_{t} \hat{z}_{t+1}
$$

Output gap as:

$$
\hat{x}_{t}=\hat{y}_{t}-\hat{q}_{t}
$$

Monetary policy rule can be linearised as:

$$
\hat{r}_{t}=\hat{r}_{t-1}+\rho_{\pi} \hat{\pi}_{t}+\rho_{g} \hat{g}_{t}+\epsilon_{r, t}
$$

Equation (E.3) implies that terms containing $\hat{z}_{t+1}$ reduces to zero in (E.4), (E.5) and (E.8).

\section{A.2 News Shock}

With anticipated technology shock equation E.3 can be written as:

$$
\hat{z}_{t}=\epsilon_{z, t}+n z_{t-i}^{i}
$$

Where $n z_{t-i}^{i}$ is the technology shock anticipated $i$ periods before (news) and is realised in tperiod. $n z_{t}^{i}$ is the shock anticipated in tperiod and having effect after $i$ period. Therefore terms containing $\hat{z}_{t+1}$ doesn't reduces to zero in (E.4), (E.5) and (E.8). Equation (E.3) is replaced by (E.3') and the model is estimated. In case anticipated markup and interest rate shock: equation E.2 and E.10 are replaced by equation E.2' and E.10' and the model is estimated.

$$
\begin{gathered}
\hat{\Theta}_{t}=\rho_{\Theta} \hat{\Theta}_{t-1}+\epsilon_{\Theta, t}+n \Theta_{t-j}^{j} \\
\hat{r}_{t}=\hat{r}_{t-1}+\rho_{\pi} \hat{\pi}_{t}+\rho_{g} \hat{g}_{t}+\epsilon_{r, t}+n r_{t-j}^{j}
\end{gathered}
$$

Where $n r_{t-j}^{j}$ and $n \Theta_{t-j}^{j}$ are the interest rate and markup shock anticipated $j$ periods before and realised in period $t$.

\section{A.3 Correlated News Shock}

With anticipated technology shock equation E.3 in appendix can be written as:

$$
\hat{z}_{t}=\phi_{0} \epsilon_{z, t}+\phi_{1} \epsilon_{z, t-1}
$$

The above specification of technological shock ensures that terms containing $\hat{z}_{t+1}$ doesn't reduces to zero in (E.4), (E.5) and (E.8). Equation (E.3) is replaced by (E.3') and the model is estimated. In case anticipated markup and interest rate shock: equation E.2 and E.10 are replaced by equation E.2' and E.10' and the model is estimated. 


$$
\begin{gathered}
\hat{\Theta}_{t}=\rho_{\Theta} \hat{\Theta}_{t-1}+\phi_{0} \epsilon_{\Theta, t}+\phi_{1} \epsilon_{\Theta, t-1} \\
\hat{r}_{t}=\hat{r}_{t-1}+\rho_{\pi} \hat{\pi}_{t}+\rho_{g} \hat{g}_{t}+\phi_{0} \epsilon_{r, t}+\phi_{1} \epsilon_{r, t}
\end{gathered}
$$

\section{A.4 Imperfect Information}

Technological shock process can be linearised as:

$$
\hat{z}_{t}=\Delta \hat{p}_{t}
$$

Full information equivalent linearised form for observation equation:

$$
\begin{gathered}
\hat{a}_{t}=C A_{1,1} \hat{x}_{t-1}+C A_{1,2} \hat{x}_{t-2}+C A_{1,3} \hat{z}_{t-1}+G_{1,1} \nu_{1}+G_{1,2} \nu_{2} \\
\hat{s}_{t}=C A_{2,1} \hat{x}_{t-1}+C A_{2,2} \hat{x}_{t-2}++C A_{2,3} \hat{z}_{t-1}+G_{2,1} \nu_{1}+G_{2,2} \nu_{2}
\end{gathered}
$$

Full information equivalent linearized form for state equations:

$$
\begin{gathered}
\hat{x}_{t}=(1+\rho) \hat{x}_{t-1}-\rho \hat{x}_{t-2}+K G_{1,1} \nu_{1}+K G_{1,2} \nu_{2} \\
\hat{x}_{t-1}=\hat{x}_{t-1}+K G_{2,1} \nu_{1}+K G_{2,2} \nu_{2} \\
\hat{z}_{t}=\rho \hat{z}_{t-1}+K G_{3,1} \nu_{1}+K G_{3,2} \nu_{2}
\end{gathered}
$$

Equation (E.3) is replaced by (E.3') and the model is estimated by including the above mentioned observation and state equations.

\section{B Taking Model to Data}

In the model we define growth rate gross rate:

$$
g_{t}=\frac{Y_{t}}{Y_{t-1}} \quad \pi_{t}=\frac{P_{t}}{P_{t-1}}
$$

From data we calculate:

$$
G_{t}=\log \left(\frac{Y_{t}}{Y_{t-1}}\right) \quad \Pi_{t}=\log \left(\frac{P_{t}}{P_{t-1}}\right)
$$

This implies:

$$
\log \left(g_{t}\right)=G_{t} \quad \log \left(\pi_{t}\right)=\Pi_{t}
$$

Now $g$ and $\pi$ are the average of gross rates (steady state values) in model. 


$$
g=\left(\prod_{t=1}^{n} g_{t}\right)^{1 / n}
$$

This implies:

$$
\log (g)=\frac{\sum_{t=1}^{n} \log \left(g_{t}\right)}{n}=\frac{\sum_{t=1}^{n} G_{t}}{n}=\operatorname{mean}\left(G_{t}\right) \Longrightarrow g=\exp \left(\operatorname{mean}\left(G_{t}\right)\right.
$$

Similarly we calculate:

$$
\pi=\exp \left(\operatorname{mean}\left(\Pi_{t}\right)\right.
$$

In the model the interest rate is gross quarterly rate. In data we have net annual net rate $R_{t}^{A}$ and thus we calculate $\log$ of gross quarterly rate, $\log \left(r_{t}\right)=\log \left[1+\frac{R_{t}^{A}}{100} * \frac{91}{360}\right]=R_{t}$ which is basically quarterly net rate. Where $R_{t}$ is the net rate and $r_{t}=1+\frac{R_{t}^{A}}{100} * \frac{91}{360}$ is the gross rate. Now $r$ is the average of gross rate (steady state values).

$$
\begin{gathered}
r=\left(\prod_{t=1}^{n} r_{t}\right)^{1 / n} \\
\log (r)=\frac{\sum_{t=1}^{n} \log \left(r_{t}\right)}{n}=\frac{\sum_{t=1}^{n} R_{t}}{n} \Longrightarrow r=\exp \left(\operatorname{mean}\left(R_{t}\right)\right.
\end{gathered}
$$

Now we know $z=g, \pi, r$ and we try to calculate $\beta$ using steady state $r=\frac{\pi z}{\beta}$. This gives $\beta>1$ and so we fixed $\beta=0.999$. Once we fixed it $r$ is no more free and is calculated using steady state relations.

$$
r=\frac{\pi z}{\beta} \Longrightarrow \log (r)=\log (\pi)+\log (z)-\log (\beta)
$$

Now we know all the values $\log \left(g_{t}\right), \log (g), \log \left(\pi_{t}\right), \log (\pi), \log \left(r_{t}\right)$ and $\log (r)$ and therefore we can do log linearization as given below

$$
\begin{aligned}
& \hat{g}_{t}=\log \left(g_{t}\right)-\log (g) \\
& \hat{\pi}_{t}=\log \left(\pi_{t}\right)-\log (\pi) \\
& \hat{r}_{t}=\log \left(r_{t}\right)-\log (r)
\end{aligned}
$$

And we estimate the model using $\hat{g}_{t}, \hat{\pi}_{t}$ and $\hat{r}_{t}$. 


\section{Results}

Table 2: Regression Estimates: With BSE Sensex Price Earning Ratio

\begin{tabular}{cccccc}
\hline & F0.Growth & F1.Growth & F2.Growth & F3.Growth & F4.Growth \\
\hline Sensex.PE & 0.000231 & $0.000613^{*}$ & -0.0000993 & $-0.000722^{* *}$ & 0.000232 \\
& $(0.70)$ & $(1.88)$ & $(-0.30)$ & $(-2.25)$ & $(0.68)$ \\
L.Sensex.PE & 0.0000128 & $-0.000565^{*}$ & -0.000135 & $0.000665^{* *}$ & -0.000340 \\
& $(0.04)$ & $(-1.80)$ & $(-0.42)$ & $(2.14)$ & $(-1.03)$ \\
TBR & -0.00233 & -0.00118 & -0.00659 & -0.00448 & -0.00442 \\
& $(-0.42)$ & $(-0.22)$ & $(-1.19)$ & $(-0.84)$ & $(-0.78)$ \\
L.TBR & -0.00521 & -0.00778 & -0.00229 & -0.00579 & -0.00277 \\
& $(-0.92)$ & $(-1.40)$ & $(-0.41)$ & $(-1.07)$ & $(-0.48)$ \\
L.Growth & 0.146 & 0.0474 & 0.105 & -0.160 & 0.0361 \\
& $(1.28)$ & $(0.42)$ & $(0.92)$ & $(-1.46)$ & $(0.31)$ \\
L.CINF & 0.0302 & 0.0202 & -0.0423 & -0.0285 & 0.0506 \\
& $(0.56)$ & $(0.38)$ & $(-0.78)$ & $(-0.54)$ & $(0.91)$ \\
Const & $0.0239^{* * *}$ & $0.0320^{* * *}$ & $0.0373^{* * *}$ & $0.0411^{* * *}$ & $0.0316^{* * *}$ \\
& $(3.56)$ & $(4.84)$ & $(5.55)$ & $(6.35)$ & $(4.59)$ \\
\hline $\mathrm{N}$ & 87 & 86 & 85 & 84 & 83 \\
\hline
\end{tabular}

Notes: F0.Growth is current growth of gross domestic product. F1.Growth - F4.Growth is one to four quarter ahead growth of gross domestic product. Sensex.PE and L.Sensex.PE is current and lag price earning ratio of BSE Sensex. TBR and L.TBR is current and lag 15-91 days treasury bills rate. L.CINF is lag quarter on quarter consumer price inflation. L.Growth is lag growth of gross domestic product.

Table 3: Regression Estimates: With BSE Sensex Market to Book Value Ratio

\begin{tabular}{cccccc}
\hline & F0.Growth & F1.Growth & F2.Growth & F3. Growth & F4.Growth \\
\hline Sensex.MBV & $0.00317^{*}$ & $0.00374^{* *}$ & 0.0000560 & -0.00195 & 0.00140 \\
L.Sensex.MBV & $(1.94)$ & $(2.26)$ & $(0.03)$ & $(-1.20)$ & $(0.81)$ \\
& -0.00103 & -0.00244 & 0.000388 & $0.00339^{* *}$ & -0.000659 \\
TBR & $(-0.67)$ & $(-1.56)$ & $(0.24)$ & $(2.21)$ & $(-0.40)$ \\
& -0.00243 & -0.00132 & -0.00798 & -0.00632 & -0.00524 \\
L.TBR & $(-0.46)$ & $(-0.25)$ & $(-1.44)$ & $(-1.20)$ & $(-0.93)$ \\
& -0.00453 & -0.00739 & -0.00137 & -0.00427 & -0.00218 \\
L.Growth & $(-0.83)$ & $(-1.35)$ & $(-0.24)$ & $(-0.79)$ & $(-0.38)$ \\
& 0.0497 & -0.0197 & 0.0548 & $-0.246^{*}$ & -0.0134 \\
L.CINF & $(0.43)$ & $(-0.17)$ & $(0.45)$ & $(-2.12)$ & $(-0.11)$ \\
& 0.0309 & 0.0240 & -0.0345 & -0.0228 & 0.0548 \\
Const & $(0.59)$ & $(0.46)$ & $(-0.64)$ & $(-0.44)$ & $(0.99)$ \\
& $0.0220^{* * *}$ & $0.0293^{* * *}$ & $0.0331^{* * *}$ & $0.0373^{* * *}$ & $0.0284^{* * *}$ \\
& $(3.57)$ & $(4.72)$ & $(5.17)$ & $(6.10)$ & $(4.34)$ \\
\hline $\mathrm{N}$ & 87 & 86 & 85 & 84 & 83 \\
\hline \multicolumn{5}{c}{ t-values in parentheses “* $\mathrm{p}<0.10 * * \mathrm{p}<0.05 * * * \mathrm{p}<0.01^{\prime \prime}$} & \\
\hline
\end{tabular}

Notes: F0.Growth is current growth of gross domestic product. F1.Growth - F4.Growth is one to four quarter ahead growth of gross domestic product. Sensex.MBV and L.Sensex.MBV is current and lag market to book value ratio of BSE Sensex. TBR and L.TBR is current and lag 15-91 days treasury bills rate. L.CINF is lag quarter on quarter consumer price inflation. L. Growth is lag growth of gross domestic product. 
Table 4: Parameter Estimates: Baseline

\begin{tabular}{ccc}
\hline & \multicolumn{2}{c}{ Baseline } \\
\hline Parameters & Estimates & Standard Error \\
$\alpha$ & 0 & 0 \\
$\gamma$ & 0.6648 & 0.0516 \\
$\rho_{\pi}$ & 0.1355 & 0.0195 \\
$\rho_{g}$ & 0.1843 & 0.0601 \\
$\rho_{a}$ & 0.9748 & 0.0045 \\
$\rho_{\Theta}$ & 0.3022 & 0.1535 \\
$\sigma_{a}$ & 0.1455 & 0.0288 \\
$\sigma_{\Theta}$ & 0.0089 & 0.0014 \\
$\sigma_{z}$ & 0.007 & 0.0026 \\
$\sigma_{r}$ & 0.0027 & 0.0003 \\
$\rho_{z c}$ & & \\
$\sigma_{z c}$ & \\
$L L$ & 885.9669 & \\
\hline
\end{tabular}

Notes: $\gamma$ is measure of habit persistence, $\alpha$ is extent of backward looking inflation, $\rho_{\pi}$ and $\rho_{g}$ are weight of inflation and growth respectively in Taylor rule. $\rho_{a}$ and $\rho_{\Theta}$ are persistence of preference and mark up shock respectively. $\sigma_{a}, \sigma_{\Theta}, \sigma_{z}, \sigma_{r}$ are standard deviation of preference, markup, technology and interest rate shocks respectively. $\rho_{z c}$ and $\sigma_{z c}$ represent the persistence and variance of the temporary technological shock process.

Table 5: Log Likelihood With Different Anticipation Period

\begin{tabular}{cccc}
\hline Quarter & Technology & Interest Rate & Markup \\
\hline & Log Likelihood & Log Likelihood & Log Likelihood \\
\hline 8 & -886.09 & -887.59 & -885.97 \\
7 & -886.06 & -886.76 & -885.97 \\
6 & -886.02 & -888.76 & -885.97 \\
5 & -885.97 & -887.90 & -885.97 \\
4 & -885.96 & -887.38 & -885.97 \\
3 & -885.97 & -877.78 & -885.97 \\
2 & -885.97 & -886.94 & -885.97 \\
1 & -885.97 & -890.52 & -885.97 \\
4,8 & -886.09 & & \\
\hline
\end{tabular}


Table 6: Forecast Error Variance Decomposition: Baseline

\begin{tabular}{ccccc}
\hline Quarter & Preference & Markup & Technology & Interest Rate \\
\hline \multicolumn{5}{c}{ Output } \\
\hline 1 & 58.9 & 13.1 & 2.4 & 25.6 \\
4 & 57.4 & 13.3 & 6.4 & 22.9 \\
8 & 54.8 & 13.9 & 7.6 & 23.6 \\
12 & 54.3 & 14.2 & 7.7 & 23.7 \\
20 & 54.4 & 14.2 & 7.7 & 23.7 \\
\hline \multicolumn{5}{c}{ Inflation } \\
\hline 1 & 13.7 & 57.8 & 4.5 & 24.0 \\
4 & 16.6 & 44.3 & 6.7 & 32.4 \\
8 & 16.2 & 43.9 & 6.9 & 33.0 \\
12 & 16.1 & 43.8 & 7.0 & 33.1 \\
20 & 16.2 & 43.8 & 7.0 & 33.0 \\
\hline \multicolumn{5}{c}{ Interest Rate } \\
1 & 50.9 & 10.1 & 0.3 & 38.7 \\
4 & 88.7 & 2.9 & 0.4 & 8.1 \\
8 & 94.9 & 1.3 & 0.2 & 3.6 \\
12 & 96.4 & 0.9 & 0.2 & 2.5 \\
20 & 97.6 & 0.6 & 0.1 & 1.7 \\
\hline
\end{tabular}
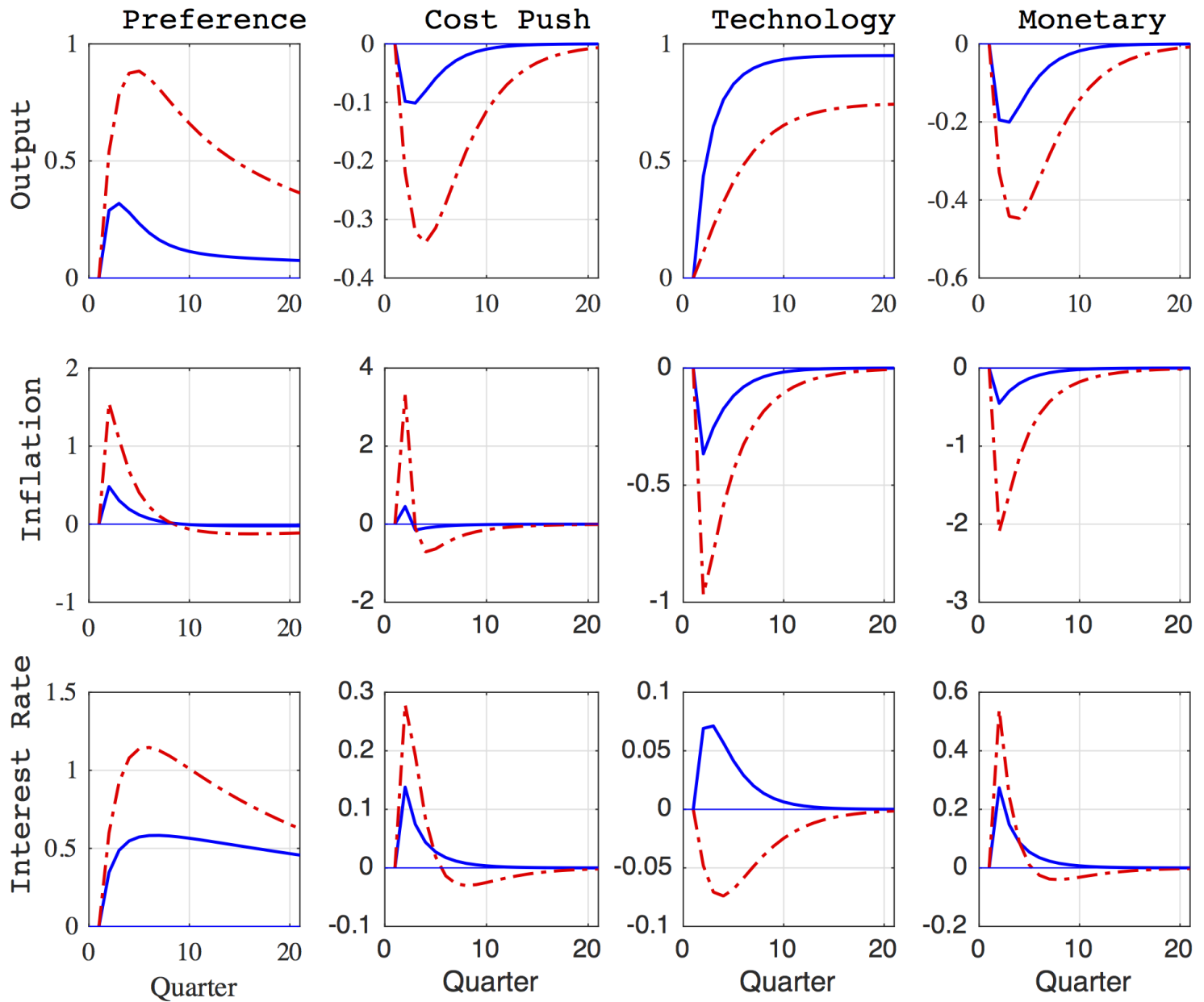

Figure 4: Impulse Response of variables(LHS) to shocks; solid line (blue) is for US as in Ireland (2011) and dotted line (red) is with baseline specification for India. 
Table 7: Parameter Estimates With News Shock

\begin{tabular}{ccccc}
\hline & \multicolumn{2}{c}{ News in Technology } & \multicolumn{2}{c}{ News in Interest Rate } \\
\hline Parameters & Estimates & Standard Error & Estimates & Standard Error \\
$\alpha$ & 0 & 0.0073 & 0 & 0 \\
$\gamma$ & 0.6579 & 0.0512 & 0.6483 & 0.0419 \\
$\rho_{\pi}$ & 0.1347 & 0.0197 & 0.1285 & 0.0186 \\
$\rho_{g}$ & 0.1961 & 0.0595 & 0.1584 & 0.0585 \\
$\rho_{a}$ & 0.9753 & 0.0044 & 0.9864 & 0.0024 \\
$\rho_{\Theta}$ & 0.3275 & 0.133 & 0.2509 & 0.1664 \\
$\sigma_{a}$ & 0.1466 & 0.0296 & 0.186 & 0.041 \\
$\sigma_{\Theta}$ & 0.0089 & 0.0013 & 0.0092 & 0.0014 \\
$\sigma_{z}$ & 0 & 0.0073 & 0.0076 & 0.0028 \\
$\sigma_{r}$ & 0.0027 & 0.0003 & 0.0021 & 0.0003 \\
$\sigma_{z 8}$ & 0.0075 & 0.003 & & \\
$\sigma_{r_{1}}$ & & & 0.0015 & 0.0003 \\
$L L$ & -886.0874 & & -890.5158 & \\
\hline
\end{tabular}

Notes: $\gamma$ is measure of habit persistence, $\alpha$ is extent of backward looking inflation, $\rho_{\pi}$ and $\rho_{g}$ are weight of inflation and growth respectively in Taylor rule. $\rho_{a}$ and $\rho_{\Theta}$ are persistence of preference and mark up shock respectively. $\sigma_{a}, \sigma_{\Theta}, \sigma_{z}, \sigma_{r}$ are standard deviation of preference, markup, technology and interest rate shocks respectively. $\sigma_{z_{8}}$ and $\sigma_{r_{1}}$ represent the variance of technological and interest rate shock anticipated in one period advance. One period news shock in interest rate was chosen using the maximum likelihood criteria from 8 competing models (one period, two period till 8 period). Eight period news shock gave highest likelihood for technology news shock but other anticipation horizon gives very similar likelihood value. At lower anticipation horizon the variance of news shock is 0 and at higher anticipation horizon variance of contemporaneous technology shock is 0 .

Table 8: Parameter Estimates With News Shock

\begin{tabular}{ccc}
\hline & \multicolumn{2}{c}{ News in Markup } \\
\hline Parameters & Estimates & Standard Error \\
$\alpha$ & 0 & 0.0042 \\
$\gamma$ & 0.6652 & 0.0514 \\
$\rho_{\pi}$ & 0.1354 & 0.0195 \\
$\rho_{g}$ & 0.1841 & 0.0599 \\
$\rho_{a}$ & 0.9748 & 0.0045 \\
$\rho_{\Theta}$ & 0.3025 & 0.1535 \\
$\sigma_{a}$ & 0.1458 & 0.0291 \\
$\sigma_{\Theta}$ & 0.0089 & 0.0014 \\
$\sigma_{z}$ & 0.007 & 0.0026 \\
$\sigma_{r}$ & 0.0027 & 0.0003 \\
$\sigma_{\Theta}$ & 0 & 0.0042 \\
$L L$ & -885.966942 & \\
\hline
\end{tabular}

Notes: $\gamma$ is measure of habit persistence, $\alpha$ is extent of backward looking inflation, $\rho_{\pi}$ and $\rho_{g}$ are weight of inflation and growth respectively in Taylor rule. $\rho_{a}$ and $\rho_{\Theta}$ are persistence of preference and mark up shock respectively. $\sigma_{a}, \sigma_{\Theta}, \sigma_{z}, \sigma_{r}$ are standard deviation of preference, markup, technology and interest rate shocks respectively. $\sigma_{\Theta_{1}}$ is the variance of markup shock anticipated in one period advance. We estimate models up to 8 periods of anticipation and likelihood doesn't change much. In all these estimation we get $\sigma_{\Theta_{1}}=0$. 
Table 9: Forecast Error Variance Decomposition: News in Technology

\begin{tabular}{|c|c|c|c|c|c|}
\hline Quarter & Preference & Markup & Noise & News & Interest Rate \\
\hline \multicolumn{6}{|c|}{ Output } \\
\hline 1 & 58.0 & 14.8 & 0.0 & 0.0 & 27.2 \\
\hline 4 & 58.5 & 15.7 & 0.0 & 0.5 & 25.3 \\
\hline 8 & 55.2 & 16.4 & 0.0 & 2.8 & 25.7 \\
\hline 12 & 53.4 & 16.2 & 0.0 & 5.2 & 25.2 \\
\hline 20 & 53.1 & 16.2 & 0.0 & 5.7 & 25.0 \\
\hline \multicolumn{6}{|c|}{ Inflation } \\
\hline 1 & 12.9 & 62.5 & 0.0 & 0.4 & 24.2 \\
\hline 4 & 16.2 & 49.1 & 0.0 & 0.8 & 33.9 \\
\hline 8 & 15.6 & 48.1 & 0.0 & 2.2 & 34.1 \\
\hline 12 & 15.2 & 47.2 & 0.0 & 4.2 & 33.4 \\
\hline 20 & 15.3 & 47.0 & 0.0 & 4.5 & 33.3 \\
\hline \multicolumn{6}{|c|}{ Interest Rate } \\
\hline 1 & 53.5 & 9.5 & 0.0 & 0.2 & 36.9 \\
\hline 4 & 89.7 & 2.6 & 0.0 & 0.3 & 7.4 \\
\hline 8 & 95.2 & 1.2 & 0.0 & 0.2 & 3.4 \\
\hline 12 & 96.6 & 0.8 & 0.0 & 0.2 & 2.3 \\
\hline 20 & 97.7 & 0.6 & 0.0 & 0.2 & 1.6 \\
\hline
\end{tabular}
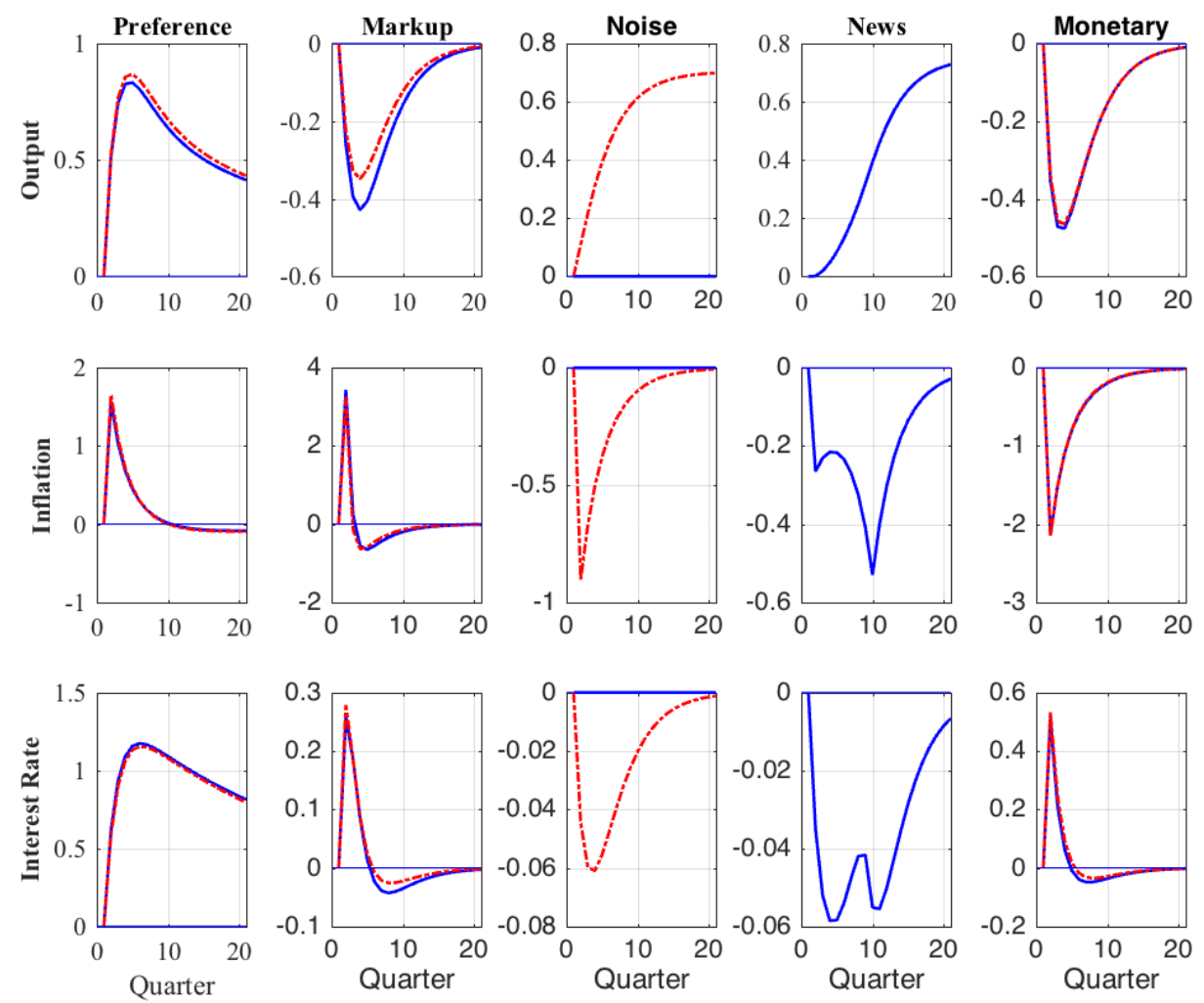

Figure 5: Impulse Response of variables(LHS) to shocks; solid line (blue) is with eight period anticipated news shock in technology and dotted line (red) is with baseline specification. 

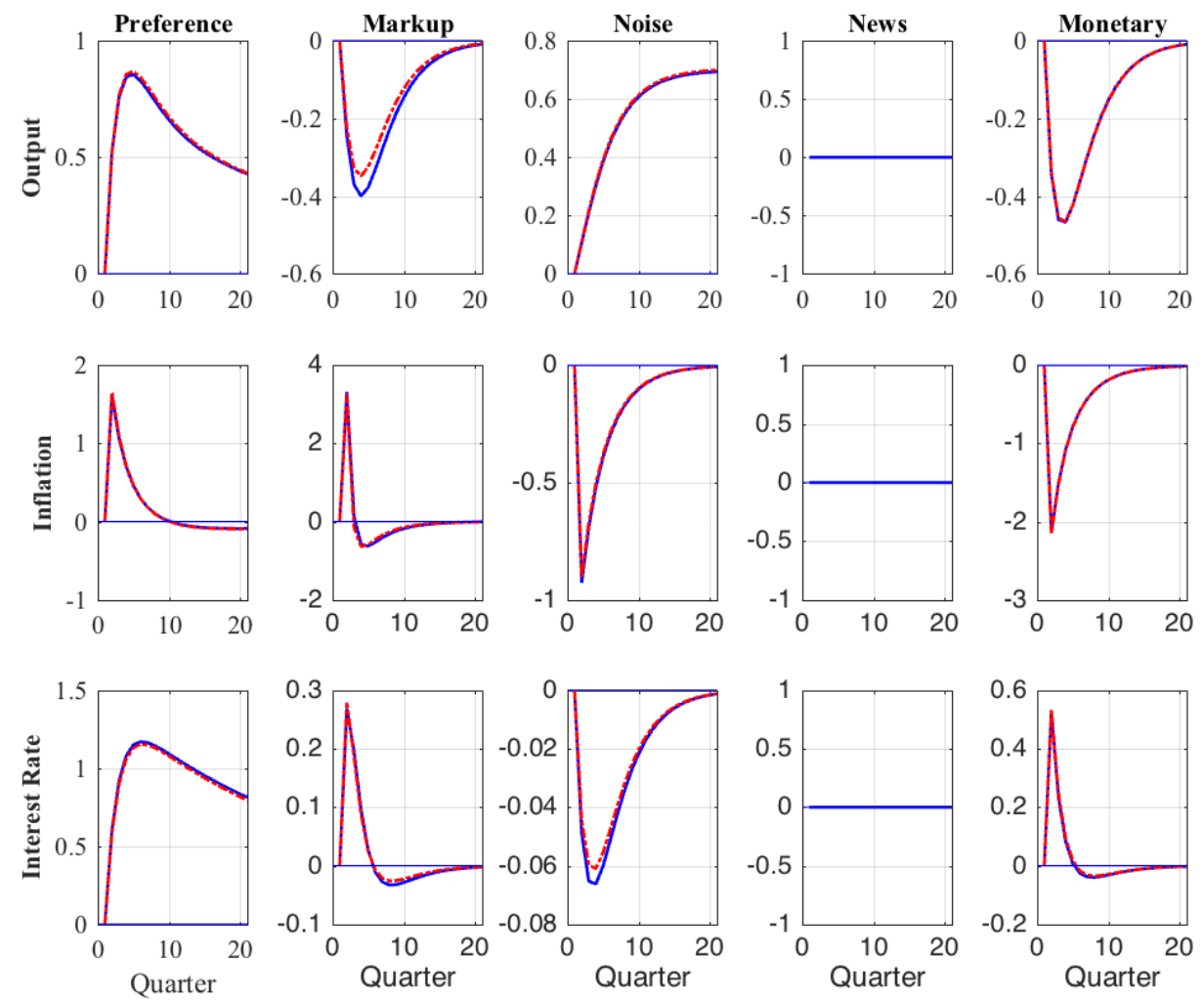

Figure 6: Impulse Response of variables(LHS) to shocks; solid line (blue) is with one period anticipated news shock in technology and dotted line (red) is with baseline specification.

Table 10: Forecast Error Variance Decomposition: News in Interest Rate

\begin{tabular}{cccccc}
\hline Quarter & Preference & Markup & Technology & News & Noise \\
\hline \multicolumn{5}{c}{ Output } \\
\hline 1 & 44.8 & 16.2 & 4.1 & 10.4 & 24.6 \\
4 & 42.7 & 15.8 & 9.9 & 9.7 & 21.9 \\
8 & 40.2 & 16.3 & 11.3 & 9.9 & 22.2 \\
12 & 39.8 & 16.5 & 11.3 & 10.0 & 22.3 \\
20 & 39.8 & 16.6 & 11.3 & 10.0 & 22.3 \\
\hline \multicolumn{7}{c}{ Inflation } \\
\hline 1 & 10.9 & 58.2 & 4.9 & 8.2 & 17.8 \\
4 & 13.7 & 44.1 & 7.0 & 11.5 & 23.7 \\
8 & 13.6 & 43.4 & 7.2 & 11.7 & 24.1 \\
12 & 13.5 & 43.3 & 7.3 & 11.7 & 24.2 \\
20 & 13.5 & 43.3 & 7.3 & 11.7 & 24.2 \\
\hline \multicolumn{7}{c}{ Interest Rate } \\
\hline 1 & 38.2 & 12.8 & 0.3 & 15.6 & 33.2 \\
4 & 82.5 & 4.3 & 0.4 & 4.2 & 8.6 \\
8 & 92.1 & 1.9 & 0.2 & 1.9 & 3.9 \\
12 & 94.7 & 1.3 & 0.2 & 1.3 & 2.6 \\
20 & 96.6 & 0.8 & 0.1 & 0.8 & 1.7 \\
\hline \multicolumn{7}{c}{}
\end{tabular}



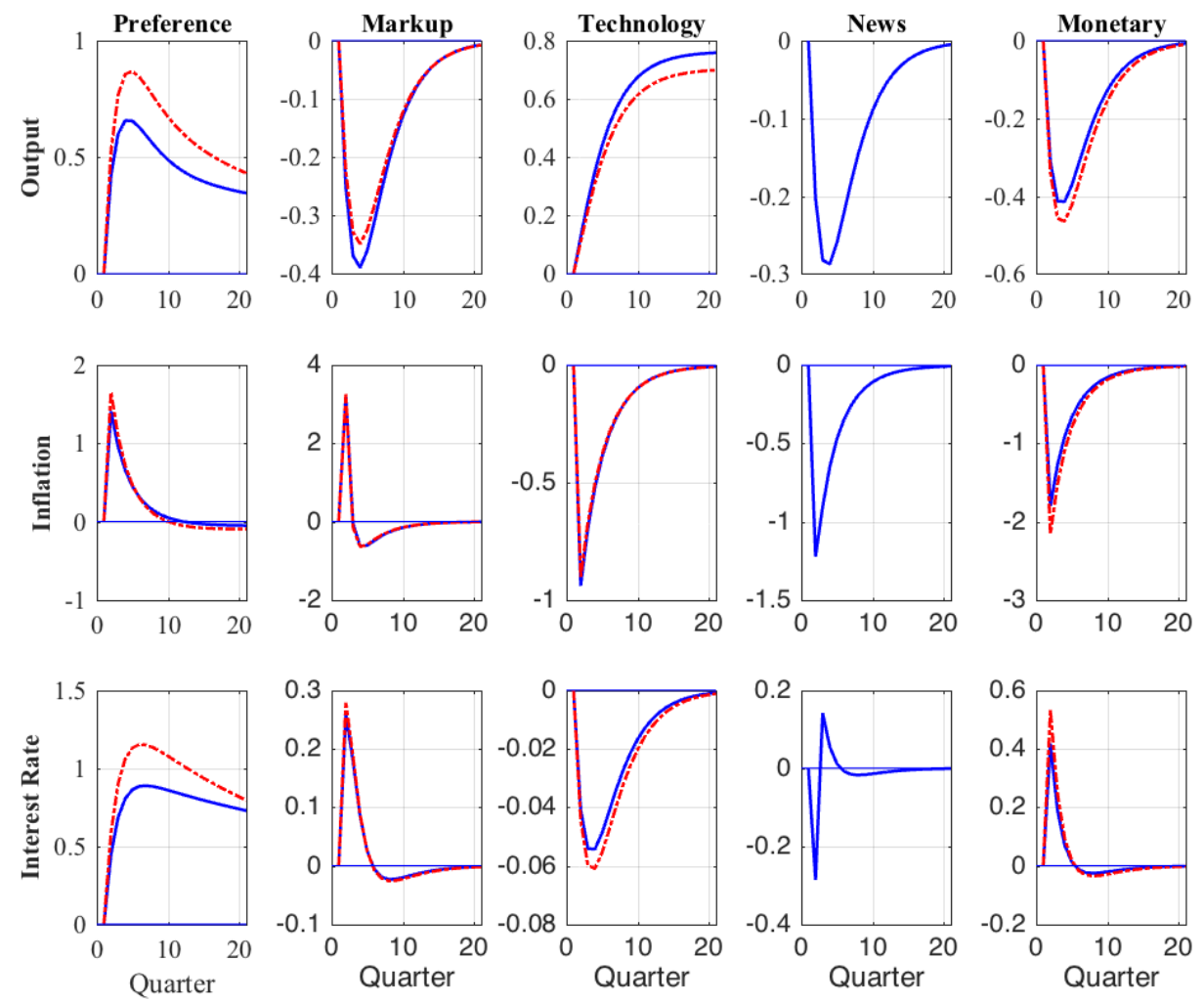

Figure 7: Impulse Response of variables(LHS) to shocks; solid line (blue) is with one period anticipated news shock in interest rate and dotted line (red) is with baseline specification.

Table 11: Forecast Error Variance Decomposition: News in Markup

\begin{tabular}{cccccc}
\hline Quarter & Preference & Markup & Technology & News & Noise \\
\hline \multicolumn{5}{c}{ Output } \\
\hline 1 & 59.0 & 13.1 & 2.4 & 0.0 & 25.5 \\
4 & 57.5 & 13.2 & 6.4 & 0.0 & 22.9 \\
8 & 54.9 & 13.9 & 7.6 & 0.0 & 23.6 \\
12 & 54.4 & 14.2 & 7.7 & 0.0 & 23.7 \\
20 & 54.5 & 14.2 & 7.7 & 0.0 & 23.6 \\
\hline \multicolumn{7}{c}{ Inflation } \\
\hline 1 & 13.7 & 57.8 & 4.5 & 0.0 & 23.9 \\
4 & 16.7 & 44.3 & 6.6 & 0.0 & 32.4 \\
8 & 16.2 & 43.9 & 6.9 & 0.0 & 33.0 \\
12 & 16.1 & 43.8 & 7.0 & 0.0 & 33.1 \\
20 & 16.3 & 43.8 & 6.9 & 0.0 & 33.0 \\
\hline \multicolumn{7}{c}{ Interest Rate } \\
\hline 1 & 50.9 & 10.1 & 0.3 & 0.0 & 38.7 \\
4 & 88.7 & 2.9 & 0.4 & 0.0 & 8.1 \\
8 & 94.9 & 1.3 & 0.2 & 0.0 & 3.6 \\
12 & 96.4 & 0.9 & 0.2 & 0.0 & 2.5 \\
20 & 97.6 & 0.6 & 0.1 & 0.0 & 1.7 \\
\hline
\end{tabular}



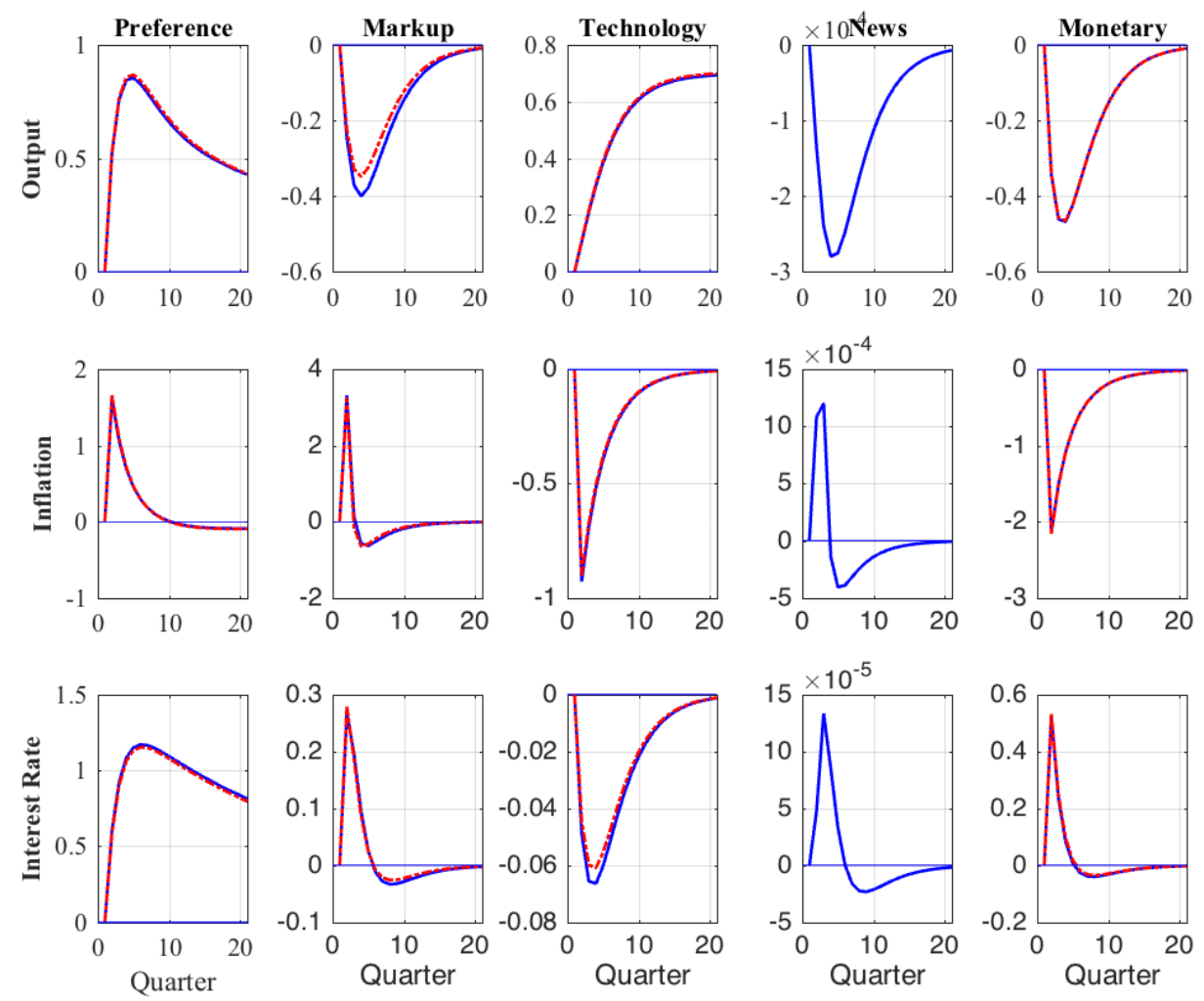

Figure 8: Impulse Response of variables(LHS) to shocks; solid line (blue) is with one period anticipated news shock in markup and dotted line (red) is with baseline specification. 
Table 12: Parameter Estimates: Correlated News Shock

\begin{tabular}{|c|c|c|c|c|}
\hline & \multicolumn{2}{|c|}{ News in Technology } & \multicolumn{2}{|c|}{ News in Interest Rate } \\
\hline Parameters & Estimates & Standard Error & Estimates & Standard Error \\
\hline$\alpha$ & 0 & 0 & 0. & 0. \\
\hline$\gamma$ & 0.6653 & 0.0477 & 0.6475 & 0.0573 \\
\hline$\rho_{\pi}$ & 0.1353 & 0.0168 & 0.1788 & 0.0372 \\
\hline$\rho_{g}$ & 0.1840 & 0.0510 & 0.2950 & 0.1140 \\
\hline$\rho_{a}$ & 0.9748 & 0.0000 & 0.9706 & 0.0071 \\
\hline$\rho_{\Theta}$ & 0.3024 & 0.1494 & 0.3412 & 0.1587 \\
\hline$\sigma_{a}$ & 0.1454 & 0.0162 & 0.1318 & 0.0348 \\
\hline$\sigma_{\Theta}$ & 0.0089 & 0.0013 & 0.0082 & 0.0014 \\
\hline$\sigma_{z}$ & 0.0070 & 0.0026 & 0.0069 & 0.0024 \\
\hline$\sigma_{r}$ & 0.0027 & 0.0000 & 0.0041 & 0.0010 \\
\hline$\phi_{1}$ & 1.0000 & 0.0000 & 0.7842 & 0.0593 \\
\hline$L L$ & -885.9669 & & -888.6396 & \\
\hline
\end{tabular}

Notes: $\gamma$ is measure of habit persistence, $\alpha$ is extent of backward looking inflation, $\rho_{\pi}$ and $\rho_{g}$ are weight of inflation and growth respectively in Taylor rule. $\rho_{a}$ and $\rho_{\Theta}$ are persistence of preference and mark up shock respectively. $\sigma_{a}, \sigma_{\Theta}, \sigma_{z}, \sigma_{r}$ are standard deviation of preference, markup, technology and interest rate shocks respectively. $\phi_{1}$ is the coefficient associated with contemporaneous error term. 1- $\phi_{1}$ represent the coefficient of $M A(1)$ in the respective shock process.

Table 13: Parameter Estimates: Correlated News Shock

\begin{tabular}{ccc}
\hline & \multicolumn{2}{c}{ News in Markup } \\
\hline Parameters & Estimates & Standard Error \\
$\alpha$ & 0 & 0 \\
$\gamma$ & 0.6415 & 0.0569 \\
$\rho_{\pi}$ & 0.1799 & 0.0385 \\
$\rho_{g}$ & 0.3006 & 0.1167 \\
$\rho_{a}$ & 0.9711 & 0.0076 \\
$\rho_{\Theta}$ & 0.1239 & 0.2031 \\
$\sigma_{a}$ & 0.1322 & 0.0368 \\
$\sigma_{\Theta}$ & 0.0105 & 0.0018 \\
$\sigma_{z}$ & 0.0072 & 0.0024 \\
$\sigma_{r}$ & 0.0041 & 0.001 \\
$\phi_{1}$ & 0.788 & 0.0595 \\
$L L$ & -888.553603 &
\end{tabular}

Notes: $\gamma$ is measure of habit persistence, $\alpha$ is extent of backward looking inflation, $\rho_{\pi}$ and $\rho_{g}$ are weight of inflation and growth respectively in Taylor rule. $\rho_{a}$ and $\rho_{\Theta}$ are persistence of preference and mark up shock respectively. $\sigma_{a}, \sigma_{\Theta}, \sigma_{z}, \sigma_{r}$ are standard deviation of preference, markup, technology and interest rate shocks respectively. $\phi_{1}$ is the coefficient associated with contemporaneous error term. 1- $\phi_{1}$ represent the coefficient of $M A(1)$ in the respective shock process. 
Table 14: Forecast Error Variance Decomposition: Correlated News in Technology

\begin{tabular}{ccccc}
\hline Quarter & Preference & Markup & Technology & Interest Rate \\
\hline \multicolumn{5}{c}{ Output } \\
\hline 1 & 59.0 & 13.1 & 2.4 & 25.5 \\
4 & 57.5 & 13.2 & 6.4 & 22.9 \\
8 & 54.9 & 13.9 & 7.6 & 23.6 \\
12 & 54.5 & 14.2 & 7.7 & 23.7 \\
20 & 54.5 & 14.2 & 7.7 & 23.6 \\
\hline \multicolumn{5}{c}{ Inflation } \\
\hline 1 & 13.7 & 57.8 & 4.5 & 24.0 \\
4 & 16.7 & 44.3 & 6.6 & 32.4 \\
8 & 16.2 & 43.9 & 6.9 & 33.0 \\
12 & 16.1 & 43.8 & 6.9 & 33.1 \\
20 & 16.3 & 43.7 & 6.9 & 33.0 \\
\hline \multicolumn{5}{c}{ Interest Rate } \\
\hline 1 & 50.9 & 10.1 & 0.3 & 38.7 \\
4 & 88.7 & 2.9 & 0.4 & 8.1 \\
8 & 94.9 & 1.3 & 0.2 & 3.6 \\
12 & 96.4 & 0.9 & 0.2 & 2.5 \\
20 & 97.6 & 0.6 & 0.1 & 1.7 \\
\hline \multicolumn{5}{c}{}
\end{tabular}
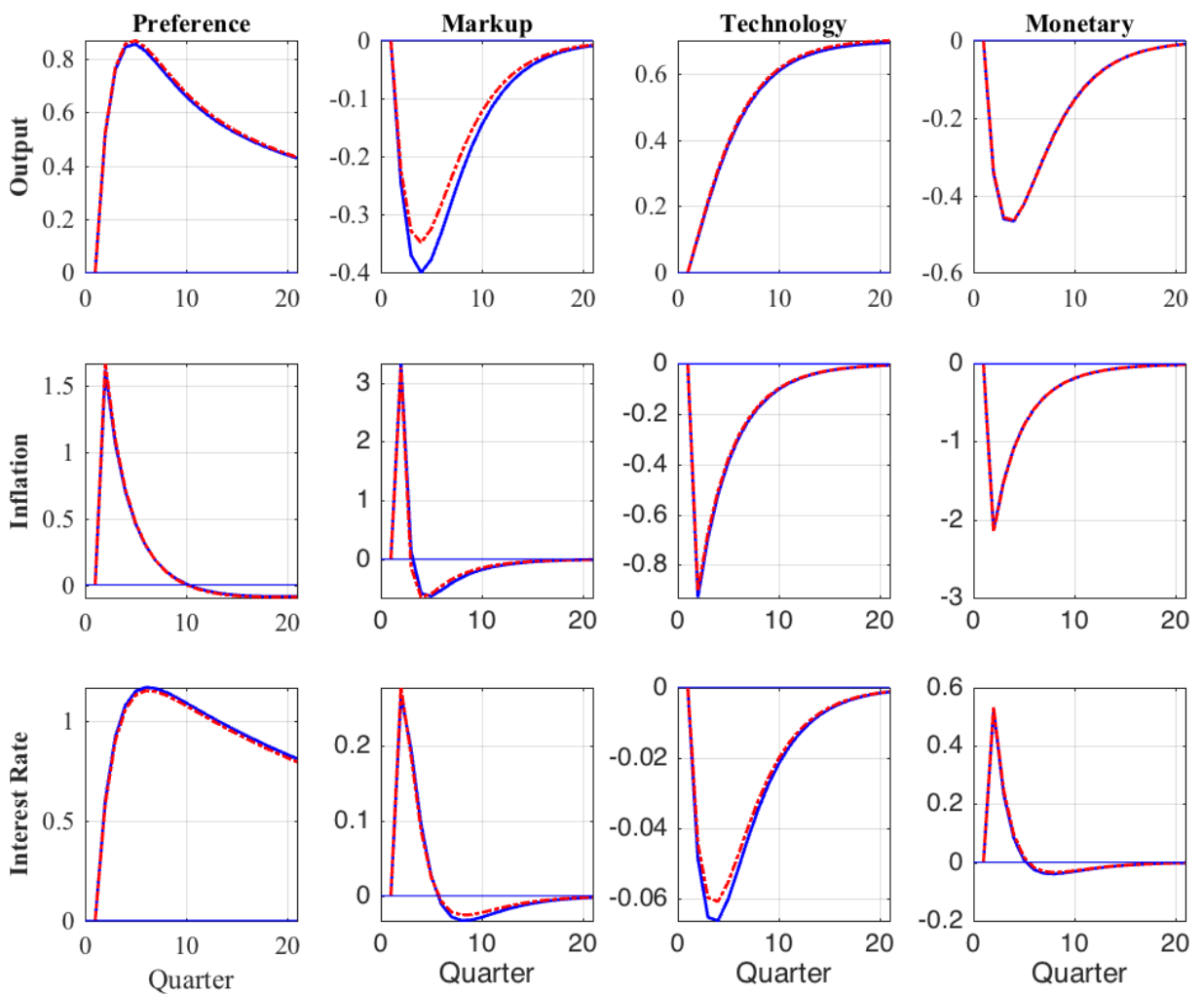

Figure 9: Impulse Response of variables(LHS) to shocks; solid line (blue) is with one period correlated news shock in technology and dotted line (red) is with baseline specification. 
Table 15: Forecast Error Variance Decomposition: Correlated News in Interest Rate

\begin{tabular}{ccccc}
\hline Quarter & Preference & Markup & Technology & Interest Rate \\
\hline \multicolumn{5}{c}{ Output } \\
\hline 1 & 45.5 & 14.3 & 1.8 & 38.4 \\
4 & 44.6 & 14.7 & 6.1 & 34.7 \\
8 & 41.9 & 15.3 & 7.5 & 35.3 \\
12 & 41.4 & 15.6 & 7.7 & 35.4 \\
20 & 41.5 & 15.6 & 7.7 & 35.3 \\
\hline \multicolumn{5}{c}{ Inflation } \\
\hline 1 & 5.5 & 57.4 & 6.2 & 30.9 \\
4 & 6.2 & 43.0 & 9.1 & 41.8 \\
8 & 5.9 & 42.3 & 9.5 & 42.3 \\
12 & 5.8 & 42.3 & 9.5 & 42.4 \\
20 & 5.9 & 42.2 & 9.5 & 42.4 \\
\hline \multicolumn{5}{c}{ Interest Rate } \\
\hline 1 & 67.4 & 11.5 & 1.1 \\
4 & 92.1 & 2.5 & 0.9 & 20.0 \\
8 & 95.9 & 1.3 & 0.6 & 2.3 \\
12 & 97.0 & 0.9 & 0.4 & 1.6 \\
20 & 97.9 & 0.6 & 0.3 & 1.2 \\
\hline
\end{tabular}
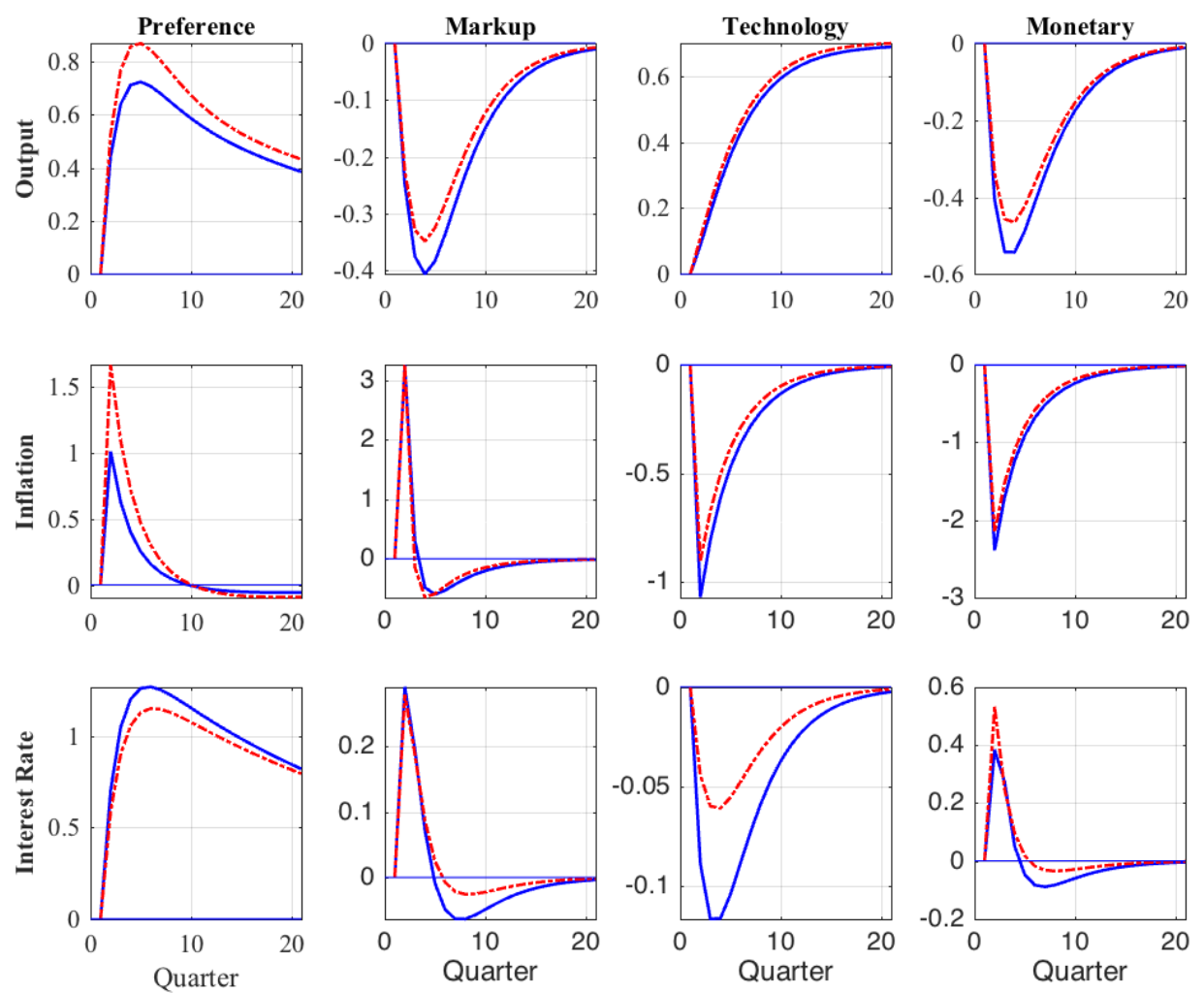

Figure 10: Impulse Response of variables(LHS) to shocks; solid line (blue) is with one period correlated news shock in interest rate and dotted line (red) is with baseline specification. 
Table 16: Forecast Error Variance Decomposition: Correlated News in Markup

\begin{tabular}{ccccc}
\hline Quarter & Preference & Markup & Technology & Interest Rate \\
\hline \multicolumn{5}{c}{ Output } \\
\hline 1 & 44.8 & 13.7 & 1.8 & 39.7 \\
4 & 43.8 & 13.8 & 6.5 & 36.0 \\
8 & 41.1 & 14.3 & 8.1 & 36.6 \\
12 & 40.7 & 14.4 & 8.2 & 36.6 \\
20 & 40.8 & 14.4 & 8.2 & 36.6 \\
\hline \multicolumn{5}{c}{ Inflation } \\
\hline 1 & 5.3 & 57.1 & 6.8 & 30.7 \\
4 & 6.0 & 43.3 & 9.8 & 40.9 \\
8 & 5.7 & 42.3 & 10.3 & 41.7 \\
12 & 5.7 & 42.1 & 10.4 & 41.8 \\
20 & 5.7 & 42.1 & 10.4 & 41.8 \\
\hline \multicolumn{5}{c}{ Interest Rate } \\
\hline 1 & 67.8 & 11.6 & 1.2 & 19.4 \\
4 & 92.1 & 2.6 & 1.0 & 4.3 \\
8 & 95.9 & 1.3 & 0.7 & 2.2 \\
12 & 97.0 & 0.9 & 0.5 & 1.6 \\
20 & 97.9 & 0.6 & 0.3 & 1.1 \\
\hline
\end{tabular}
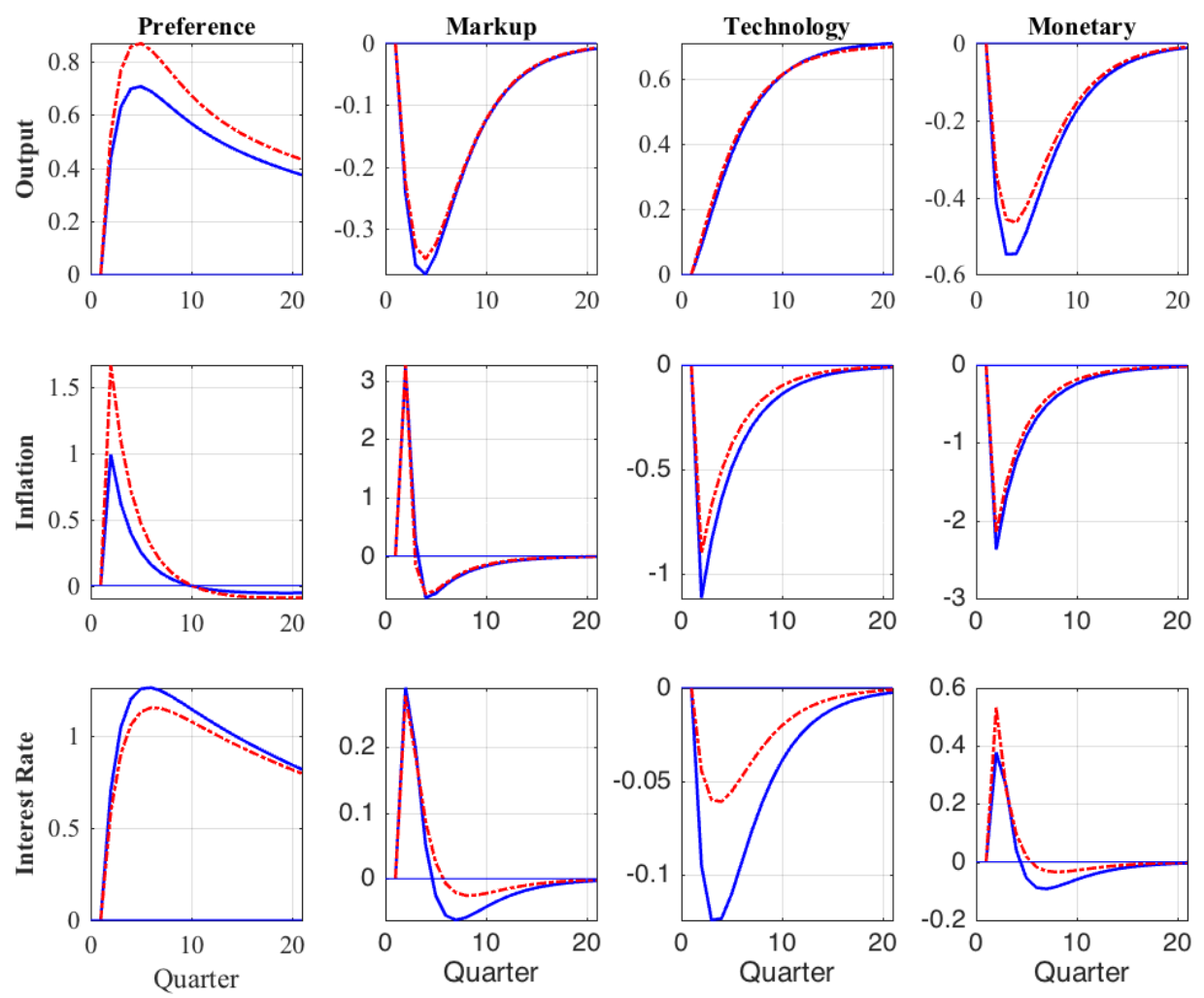

Figure 11: Impulse Response of variables(LHS) to shocks; solid line (blue) is with one period correlated news shock in markup and dotted line (red) is with baseline specification. 
Table 18: Forecast Error Variance Decomposition: Unit Root Technology with Imperfect Information

\begin{tabular}{ccccccc}
\hline Quarter & Permanent & Temporary & Noise & Preference & Markup & Interest Rate \\
\hline \multicolumn{7}{c}{ Output } \\
\hline 1 & 19.3 & 18.3 & 0.1 & 40.9 & 6.4 & 15.0 \\
4 & 14.7 & 3.6 & 0.1 & 57.1 & 8.0 & 16.5 \\
8 & 11.6 & 2.3 & 0.1 & 64.3 & 7.2 & 14.6 \\
12 & 10.4 & 2.0 & 0.0 & 67.7 & 6.6 & 13.3 \\
20 & 9.6 & 1.8 & 0.0 & 70.2 & 6.1 & 12.3 \\
\hline \multicolumn{7}{c}{ Inflation } \\
\hline 1 & 2.8 & 0.8 & 0.3 & 12.7 & 60.3 & 23.2 \\
4 & 6.4 & 0.6 & 0.2 & 14.3 & 46.6 & 31.8 \\
8 & 7.1 & 0.6 & 0.2 & 13.8 & 45.7 & 32.7 \\
12 & 7.1 & 0.6 & 0.2 & 13.9 & 45.5 & 32.7 \\
20 & 7.1 & 0.6 & 0.2 & 14.4 & 45.2 & 32.5 \\
\hline \multicolumn{7}{c}{ Interest Rate } \\
\hline 1 & 0.2 & 0.1 & 0.0 & 55.5 & 10.5 & 33.7 \\
4 & 0.4 & 0.0 & 0.0 & 89.9 & 2.6 & 7.2 \\
8 & 0.3 & 0.0 & 0.0 & 94.7 & 1.3 & 3.7 \\
12 & 0.2 & 0.0 & 0.0 & 95.9 & 1.0 & 2.8 \\
20 & 0.2 & 0.0 & 0.0 & 96.6 & 0.8 & 2.3 \\
\hline
\end{tabular}

Table 17: Parameter Estimates With Unit Root in Technology: Imperfect Information

\begin{tabular}{|c|c|c|c|c|c|c|c|}
\hline \multicolumn{7}{|c|}{ Prior } & Posterior \\
\hline Parameters & Mean & Std. & Distribution & LB & UB & Initial Value & Mode \\
\hline$\alpha$ & 0.1 & 0.2 & Beta & 0.01 & 0.5 & .08 & .0100 \\
\hline$\gamma$ & 0.6 & 0.2 & Beta & 0.1 & 0.999 & .65 & .6535 \\
\hline$\rho_{\pi}$ & 0.4 & 0.2 & Beta & 0.1 & 0.999 & .15 & .1291 \\
\hline$\rho_{g}$ & 0.4 & 0.2 & Beta & 0.1 & 0.999 & .20 & .1803 \\
\hline$\rho_{a}$ & 0.8 & 0.2 & Beta & 0.1 & 0.99 & .95 & .9376 \\
\hline$\rho_{\Theta}$ & 0.2 & 0.2 & Beta & 0.01 & 0.999 & .15 & .1384 \\
\hline$\sigma_{a}$ & 0.15 & 0.1 & INV Gamma & 0.0001 & 1 & .15 & .0675 \\
\hline$\sigma_{\Theta}$ & 0.0065 & 0.0020 & INV Gamma & 0.0001 & 1 & .0075 & .0099 \\
\hline$\sigma_{u}$ & 0.0070 & 0.0020 & INV Gamma & 0.0001 & 1 & .0075 & .0069 \\
\hline$\sigma_{r}$ & 0.0020 & 0.0010 & INV Gamma & 0.0001 & 1 & .0025 & .0024 \\
\hline$\rho$ & 0.6 & 0.3 & Beta & 0.1 & 1 & 0.8 & .3441 \\
\hline$\sigma_{s}$ & .0050 & .0025 & INV Gamma & 0.0001 & 1 & .0050 & .0036 \\
\hline
\end{tabular}

Notes: $\gamma$ is measure of habit persistence, $\alpha$ is extent of backward looking inflation, $\rho_{\pi}$ and $\rho_{g}$ are weight of inflation and growth respectively in Taylor rule. $\rho_{a}$ and $\rho_{\Theta}$ are persistence of preference and mark up shock respectively. $\sigma_{a}, \sigma_{\Theta}, \sigma_{u}, \sigma_{r}$ are standard deviation of preference, markup, technology and interest rate shocks respectively. $\rho$ represent the common persistence parameter for both permanent and temporary technological process and $\sigma_{s}$ the variance of noise shock. 

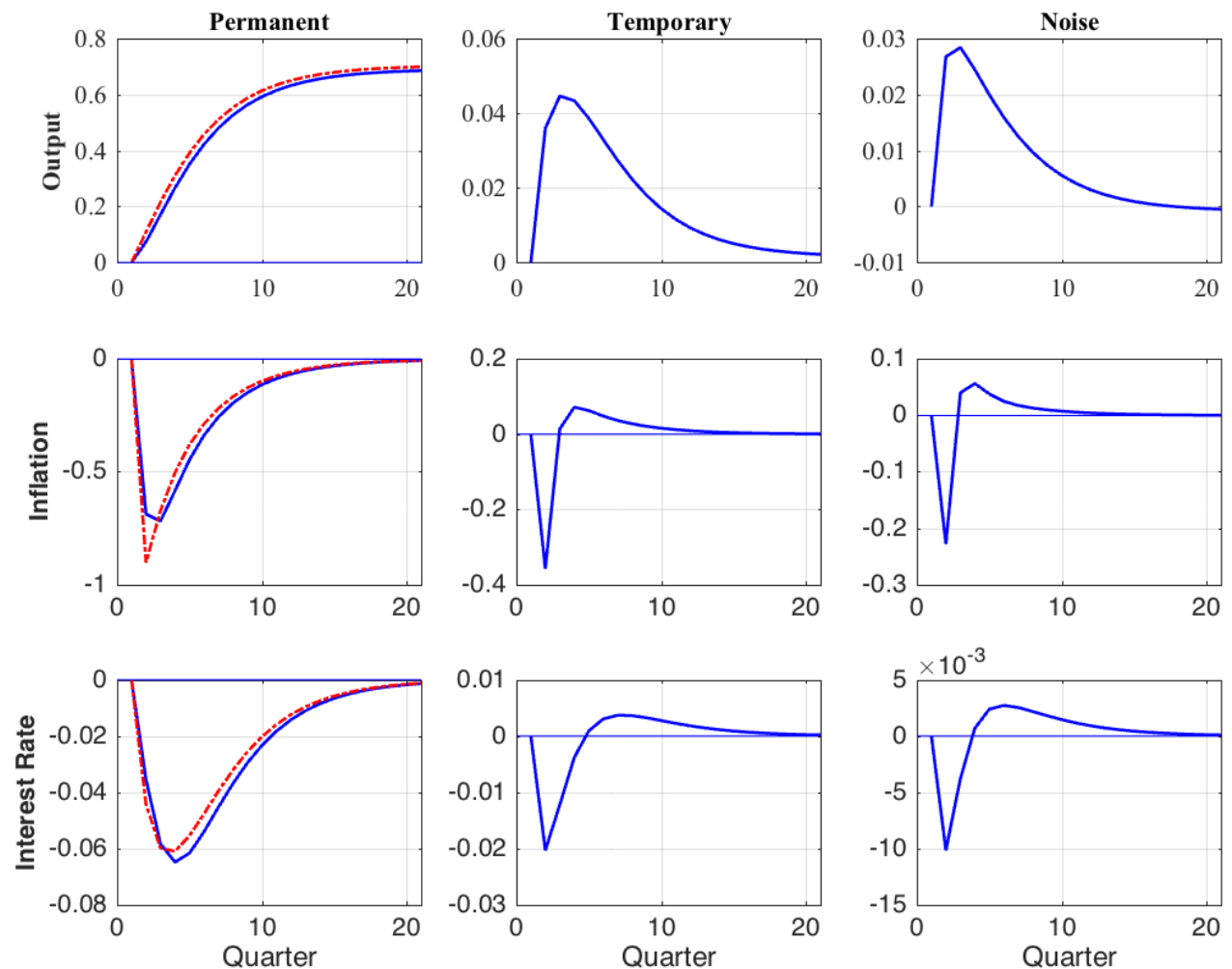

Figure 12: Impulse Response of variables(LHS) to shocks; solid line (blue) is with technology shock with imperfect information and dotted line (red) is with baseline specification. 

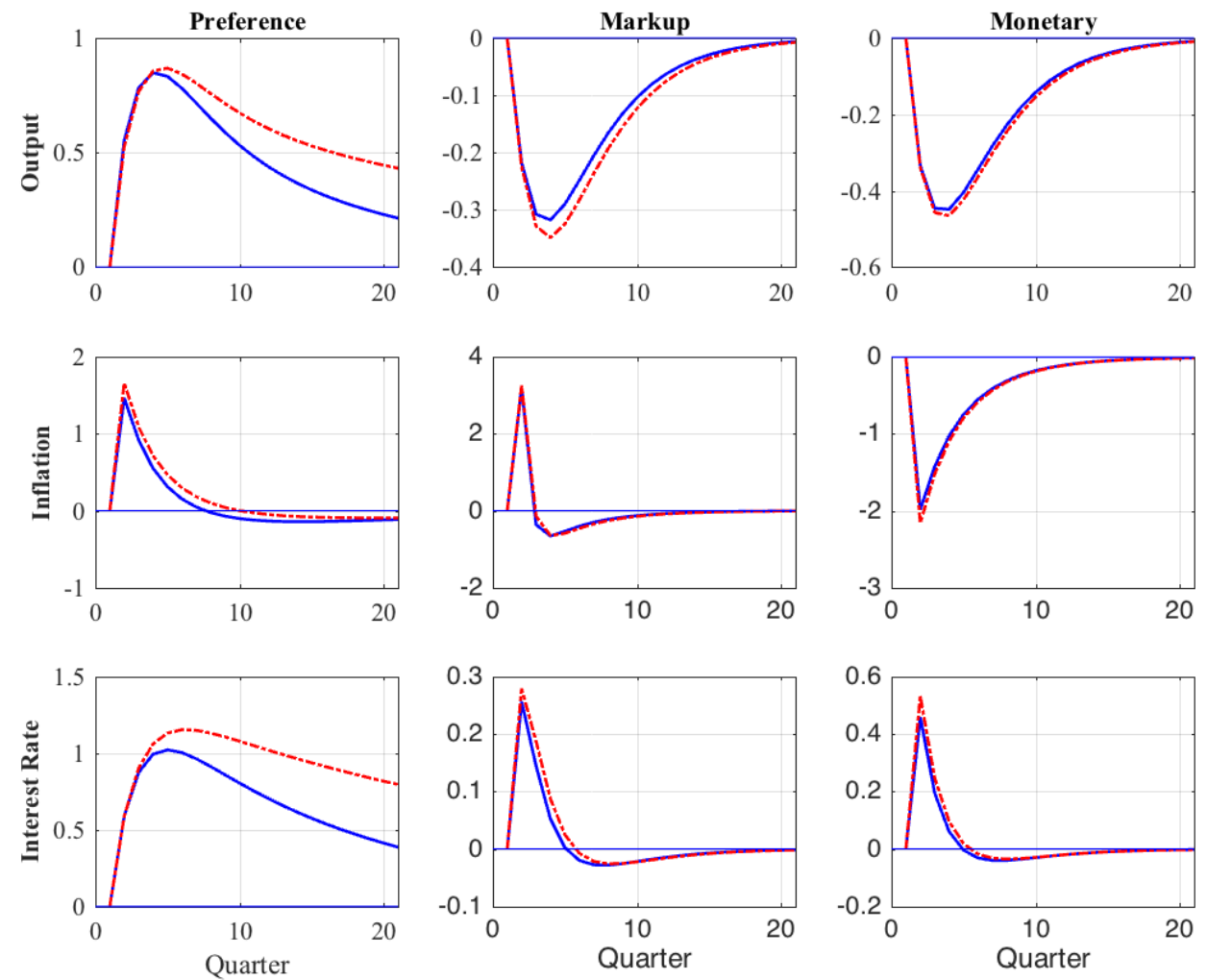

Figure 13: Impulse Response of variables(LHS) to shocks; solid line (blue) is with technology shock with imperfect information and dotted line (red) is with baseline specification. 